University of Rhode Island

DigitalCommons@URI

Open Access Dissertations

1983

\title{
The Role-Taking Construct and Its Relationship to Social Acceptance
}

William P. Geary

University of Rhode Island

Follow this and additional works at: https://digitalcommons.uri.edu/oa_diss

\section{Recommended Citation}

Geary, William P., "The Role-Taking Construct and Its Relationship to Social Acceptance" (1983). Open Access Dissertations. Paper 1108.

https://digitalcommons.uri.edu/oa_diss/1108

This Dissertation is brought to you for free and open access by DigitalCommons@URI. It has been accepted for inclusion in Open Access Dissertations by an authorized administrator of DigitalCommons@URI. For more information, please contact digitalcommons-group@uri.edu. 
THE ROLE-TAKING CONSTRUCT

AND ITS RELATIONSHIP TO SOCIAL ACCEPTANCE

BY

WILIIAM P. GEARY

A DISSERTATION SUBMITTED IN PARTIAL FULFILINIENT OF THE REQUIREIVENTS FOR THE DEGREE OF DOCTOR OF PHILOSOPHY

IN

PSYCHOLOGY

UNIVERSITY OF RHODE ISLAND

1983 
Abstract

This research was undertaken to examine the role-taking construct as being a composite of two different component abilities, interrelating multiple elements and controlling the self. Each of these abilities was examined developmentally, and in relationship to social acceptance, intelligence and socioeconomic status. Developmental psychologists have stated that role-taking is an important social-cognitive ability for appropriate social behavior and peer acceptance. In a similar manner, research has linked a delay in roletaking ability to peer acceptance problems in certain popu-. lations. In this study, the multidimensionality of roletaking and its relationship to social acceptance in normal elementary school population is examined.

A sample of 90 students from grades 2,4 , and 6 were categorized as popular, isolated, and rejected and individually administered the role-taking and intelligence measures. The socioeconomic information was obtained from the children's parents.

The results of the correlational analysis indicated that the abilities to interrelate multiple elements and control the self were statistically related. However, the practical relationship between the two abilities was negligible. The pattern of development was different for these two abilities. Interrelating multiple elements increased 
at a similar rate across grade levels. Controlling the self increased significantly from the 2nd to 4 th grade, with no significant increase from the 4 th to 6 th grade. Only controlling the self was significantly related to social acceptance; popular children performed better than isolated and rejected, and isolated did better than the rejected. Intelligence and controlling the self were the most effective variables at discriminating and classifying social acceptance groups.

The results of this study suggest that role-taking may not be a unitary construct and that each of the component abilities develop at a different rate. Only the ability to control the self seems to be important toward actual social acceptance. Implications of these results for future research are discussed. 


\section{Acknowledgement}

This research project could not have been completed without the support and invaluable assistance of many people. First, I'd like to thank Elaine Grennan and Janet Rossi for their help in the data collection. I'd also like to thank Sam Rose for his assistance in working with parents to collect the socioeconomic measures and in helping to organize the data. Appreciation is also extended to Eileen Ross for her partaking in the scoring of the dependent measures and putting up with long hours of training. Lastly, I'd like to thank Paula Rocha for her time and talent in typing the drafts and final edition of this manuscript.

Niy doctoral committee, Drs. William Vosburgh, Janet Kulberg, Albert Lott, and Alfred Pascale have been a constant source of encouragement throughout this project. Each has contributed, in his or her own way, constructive criticism and guidance in refining the concepts, methodology, and writing of this experiment. Special thanks are due to my major professor and advisor, Dr. William Vosburgh: Dr. Vosburgh has been an exceptional source of professional advice and friendship during my years at U. R. I. In addition, he has stressed professionalism and scholarship throughout this dissertation and has always been there each step of the way to encourage my progress. 
Finally, I'd like to thank my wife, Pam, and my parents for all their support. They had patience and understanding throughout and have helped to make me feel it was all worthwhile. 
ABSTRACT

ACKNOWLEDGENENTS

Psychological Constructs and Social Role-Taking . Developmental Models and Empirical Research . Role-Taking and Social Behavior Rationale and Hypotheses

Subjects

Attribute Variabies

Procedure

Correlates

RESULTS

Role-Taking Construct

Developmental Results

Role-Taking and Social Acceptance

Classification of Social Acceptance.

Summary .

DISCUSSION

Role-Taking Construct

Role-Taking Development

Role-Taking and Social Acceptance

Implications for Future Research

summary .

APPENDICES

A. Correspondence . . . . . . . 85

B. Sociometric Instruments and Chandler's Task: 90

C. Summary Tables . . . . . . . . 95

D. Role-Taking Mieasures . . . . . . 100

REFERENCES . . . . . . . . . . . . 102 
Page

1. Models of Role-raking . . . . . . . 10

2. Pearson Product-Mioment Correlation Matrix for Role-Taking Tasks and Demographic Variables . . 51

3. Summary of Feffer's Role-Taking Test. . . . 53

4. Summary of Chandler's Role-Taking Test . . . 55

5. Summary of SES Results . . . . . . . 56

6. Summary of IQ Results . . . . . . . 57

7. Means and Standard Deviations for Chandler's Role-Taking Task by Sex and Social Acceptance . 59

8. Means and Standard Deviations for SES by Sex and Social Acceptance . . . . . . 60

9. Group Means of Four Predictor Variables on Three Criterion Groups . . . . . . 62

10. Standardized and Unstandardized Canonical Coefficients for Discriminant Function Analysis . 64

11. Classification Results for Social Acceptance Using Four Predictor Variables . . . . . 66

12. Cochran's $\underline{C}$ Test for Homogeneity Variance . . 96

13. Means and Standard Deviations for the Correlates by Sex and Grade. . . . . . . . . 97

14. MANOVA Summary Table. . . • • . . . 98 


\section{Iist of Figures}

Page

1. Role-Taking and Social Acceptance. . . . 32 
Introduction

This research has been undertaken to explore further the role-taking construct, its development with age, and its relationship to social acceptance for elementary school children. Some of the different models of role-taking discuss this ability as a cognitive process, whereby one attempts to understand the thoughts, viewpoints, and feelings of another person. This social-cognitive process, however, needs to be examined more closely in terms of its basic theoretical nature, due to the inconsistent findings of previous studies relating role-taking to social behavior and social acceptance among peers. It is the intent of this study to examine how the construct of role-taking has been viewed and investigated, and how previous assumptions regarding role-taking have led to confusing results. A new perspective emerging from the recent literature is that role-taking may not be a unitary construct or ability, but a composite of component abilities. However, this has not been investigated empirically.

The perspective that role-taking is not a unitary construct would also have implications concerning socialcognitive development. The component abilities of roletaking may develop at different rates, thus affecting how children of different ages perform on typical role-taking tasks. In addition, each of the composite abilities may have 
different effects on how children interact with their social world at different ages.

The significance of peers in the social life of children continues to be an important area of investigation. Despite Piaget's theoretical proposition that role-taking is essential for effective social functioning, the relationship between role-taking and social acceptance remains largely an unexplored area. Both basic research and intervention studies in this area have been hampered by equivocal results. This is possibly due to a lack of understanding of the role-taking construct. This study is undertaken to examine the relationship of role-taking to different categories of social acceptance across grade levels. In addition, this study examines the relationship of certain demographic characteristics to social acceptance and role-taking ability.

The following literature review is divided into four sections. The first section discusses the importance of validating constructs in psychological research and, in particular, the construct of role-taking. The second section delineates some of the developmental models of role-taking, and how recent empirical research and theoretical speculation suggest a need for revision of the role-taking construct. The third section examines the literature relating role-taking to social behavior and social acceptance. The last section outlines the rationale for studying role-taking and social acceptance, and presents the hypotheses and specific predictions. 
Psychological Constructs and Social Role-Taking

The understanding of the social world of children, particularly their social cognitions, has been a major concern of developmental psychologists within the past decade (Damon, 1978; Flavell \& Ross, 1981; Higgins \& Parsons, 1983; Selman, 1971b, 1974, 1981; Shantz, 1975). The rapid emergence of social-cognition as a field of study has, however, led to some uncertainty about the relationship of this new field to some longer established areas of research, i.e., non-social cognitive development and social skills training. It is the relationship of social-cognition to social skills and acceptance that is the concern of this study. Previous research attempts to relate social-cognition to social behavior has proven to be inconsistent or disappointing (Kurdek, 1977; Shantz, 1975). This may, in part, be due to the reliability and validity of the measures used (Berndt, 1981), or to the models and theoretical constructs that have been developed (Ford, 1979; Higgins, 1981). The intent of this study is to examine the role-taking construct from a different perspective, and its relationship to measures of peer acceptance. Psychological Constructs

A theoretical construct is essentially an unobservable characteristic of some entity, usually a person, that is hypothesized as an explanation for some observable phenomena (Ford, 1979). Usually a construct in psychology refers to 
an underlying structure or process that can account for a person's behavior. Examples of some common psychological constructs include intelligence, anxiety, libido, etc.. Constructs that have been adequately validated through empirical testing can be efficient and reliable sources of guidance in our problem-solving activities (Cronbach \& Meehl, 1955; Ford, 1979). On the other hand, constructs that are not validated may distort our view of the relevant problems. It is, therefore, essential that constructs be evaluated as to their validity. In the social-cognitive literature, the psychological construct that has received the greatest emphasis and attention is role-taking (Chandler, Note 1; Shantz, 1975). What exactly role-taking is and how it relates to social behavior is still not well understood, despite the various models that have been put forth. Construct Validation and Role-Taking

Cronbach and Meehl (1955) assert that construct validation begins with a theory that defines the construct. They state that if an investigator does not specify the meaning of the construct clearly enough, then others will be unable to evaluate the evidence for the validity of the construct. This has been a perennial problem within the role-taking literature. First, role-taking is often used interchangeably with other social-cognitive constructs like egocentrism, social decentering, and person perception. Second, there is no unitary theory of role-taking development. There are several different models of role-taking that have developed 
from Piaget's theory of general cognitive development, e.g., Flavell (1966), and Selman and Byrne (1974). Third, the literature discusses three different role-taking processes. In her review of the literature, Shantz (1975) lists these processes as being a) What does the other see (spatial role-taking)?; b) What does the other feel (affective roletaking)?; c) What is the other thinking (cognitive roletaking)? Each of these is assumed to incorporate an appreciation for perspectives other than one's own, with the differences just being the process or domain each pertains to: spatial, affective, or cognitive.

The theory that defines the construct may also imply the construct as being an entity that is consistent across situations and stable over time. Role-taking appears to be presented as a generalized trait (DeVries, 1970; Feffer, 1970; Flavell, 1974; Selman \& Byrne, 1974). In other words, the presence or absence of this hypothetical construct is considered to be a sufficient explanation for the presence or absence of a wide range of phenotypically diverse behaviors (Ford, 1979). If this is true, then the three processes of role-taking, as listed by Shantz (1975), should be highly correlated with each other and with actual social behavior. Ford (1979) and Shantz (1975) in their reviews of the literature find little support for the convergent validity of the construct of role-taking. The most common finding is a lack of significant relationship among the instruments purported to measure the construct of role-taking, 
even for those instruments whose reliabilities indicate something consistent is being measured (Kurdek, 1977; Rubin, 1973). In addition, the relationship between roletaking and actual social behaviors has been equivocal (Burka \& Glenwick, 1978; Gottman, Gonso \& Rasmussen, 1975; Rountree, Caldwell \& Webb, 1981).

\section{Summary}

A theoretical construct should serve to organize, guide, and stimulate research into some psychological phenomenon. However, when constructs are not validated, they may distort our view of the relevant problems. Role-taking is a social cognitive construct that has a history of confusion in regards to specific meaning of the construct, and with equivocal evidence to support it.

There are some important implications for the negative or equivocal evidence found in the reviewed studies. It could be that some or all of the measures are not good assessors of the construct, or the theory that specifies the meaning of the construct is incorrect (Cronbach \& Mieehl, 1955). There is evidence to support the implication that the measures are not good assessors of the construct, as many of the instruments have low reliabilities (Ford, 1979; Shantz, 1975). However, some of the instruments do have good reliability and still their inter-correlations are low, suggesting that they are not measuring the same underlying construct. Only recently have researchers given serious consideration to the possibility that, although Piaget's 
role-taking theory is generally correct, the clarity of the theory and the operational definition of the role-taking construct could be further refined (Higgins, 1981). 
Developmental Models and Empirical Research

Role-taking models and theorists interested in roletaking development usually adhere to certain assumptions about the construct. First, the term "role" is not used as most social psychologists and sociologists use it to refer to a class of shared behavioral expectations defined by a set of functions or traits, such as sex role or occupational role (Shantz, 1975). The term is used to describe momentary relations or positions between two or more people. Roletaking generally refers to the activity and/or ability to take the position of another person, and thereby infer his or her perspective regarding thoughts, feelings, or spatial orientation. Second, role-taking is viewed as a means of reaching some interpersonal goal such as solving a social dilemma or acting in concert with another (Piaget, 1970). Third, the Piagetian levels of concrete and formal operations are considered necessary, but not sufficient, for the development of the parallel levels of role-taking (Shantz, 1975). Fourth, the levels of role-taking are considered invariant and hierarchial (Flavell, 1974; Selman, 1981). Fifth, there should be an internal consistency of responding across tasks, since role-taking ability constitutes an organized and consistent way of reasoning about the social world (Ford, 1979).

While there is no single, general theory of the development of role-taking, there are several stage models that 
embody the above tenets. The two most extensively formulated stage models are those of Flavell, Botkin, Fry, Wright and Jarvis (1968), and Selman and Byrne (1974) (see Table 1). Selman states that prior to age six, the child is egocentric, in the sense that he or she makes no distinction between his or her view of a social situation and possible alternative views. The child may know that another can hold a different perspective, but is unable to specify that perspective or just assumes similarity between perspectives. From approximately 6 to 10 years of age, the child achieves two important skills: 1) the child is able to infer the other's intention, thoughts, and feelings with a good deal of accuracy; 2) then the child becomes able to understand that his or her thoughts can be the object of another person's thinking. Around 10 to 11 years of age, a new stage occurs in which the child understands that another can take one's own perspective simultaneously with one's taking of another perspective (mutual role-taking). Around 12 years of age, the role-taking ability of the adolescent extends beyond the two person level to that of the social system, "the generalized other."

This stage model of role-taking is based largely on children's responses to short stories involving moral and social dilemmas. There are also other stage models of roletaking, which are not as extensively developed, but in general correspond quite well to Selman's stage descriptions (DeVries, 1970; Feffer, 1970; Kuhn, Note 3). Flavell (1974) 
Table 1

Models of Role-Taking

\begin{tabular}{|c|c|c|}
\hline Author & Dates & Developmental levels \\
\hline Selman & $\begin{array}{l}1971,1973, \\
1974,1981\end{array}$ & $\begin{array}{l}\text { Level 0: Egocentric or } \\
\text { undifferentiated perspec- } \\
\text { tives. No distinction } \\
\text { between the perspective } \\
\text { of self and others. }\end{array}$ \\
\hline & & $\begin{array}{l}\text { Level 1: Subjective or } \\
\text { differentiated perspec- } \\
\text { tives. The child recog- } \\
\text { nizes that self and other' } \\
\text { perspectives may be dif- } \\
\text { ferent and can begin to } \\
\text { infer another's thoughts } \\
\text { and feelings. }\end{array}$ \\
\hline
\end{tabular}

Level 2: Self reflective or reciprocal perspectives. Children are able to reflect on their own thoughts and feelings from another perspective, which leads to an awareness of reciprocity of thoughts and feelings rather than just action.

Level 3: Third person or mutual perspectives. The ability to step outside of an interpersonal interaction and coordinate simultaneously the perspectives of each party in the interaction.

Level 4: Societal or indepth perspectives. Perspectives among persons are seen as forming a network or system. These perspectives become generalized e.g. society's legal point of view. 
Table 1

(Continued)

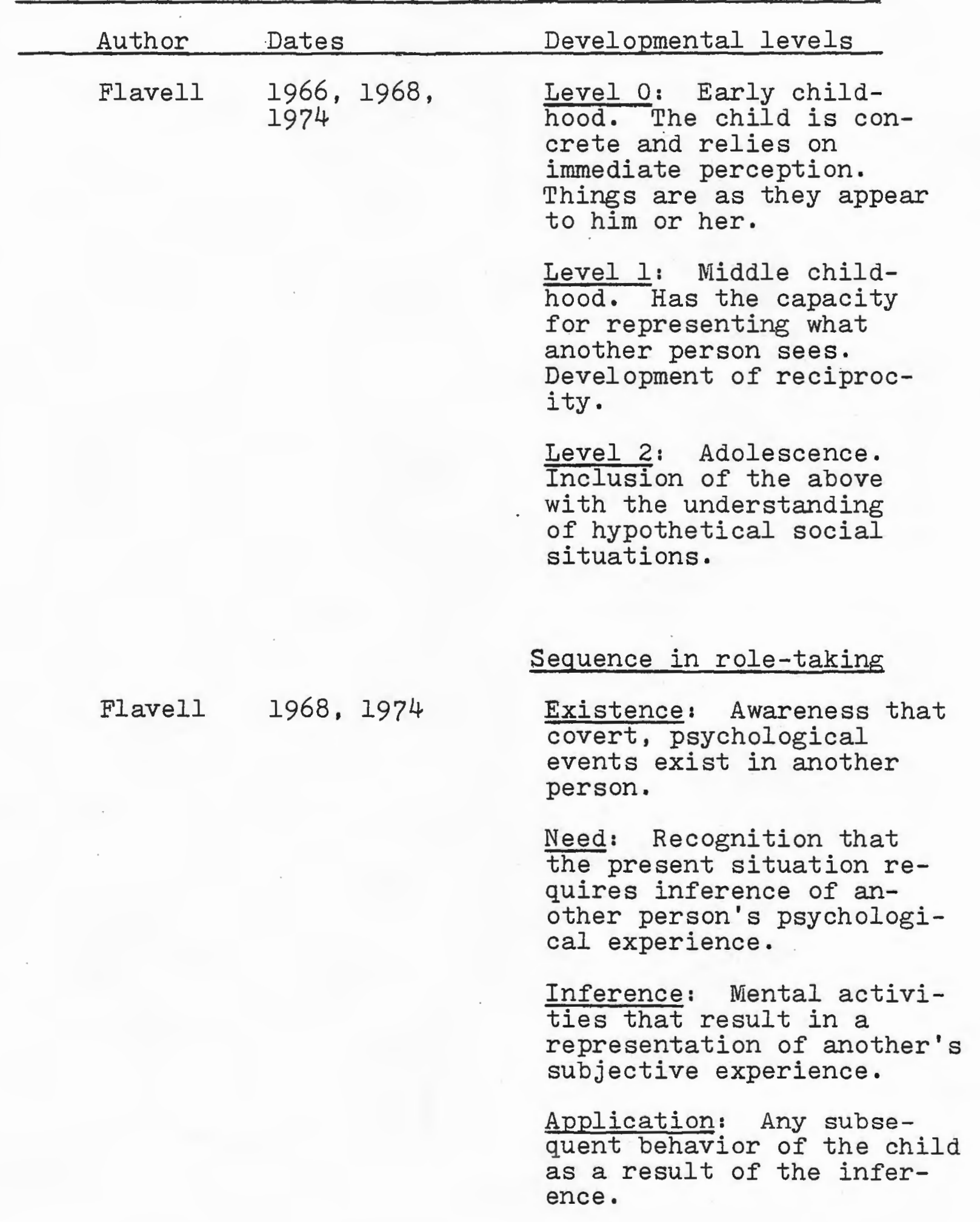


has provided the only other stage model that has been extensively formulated from the preschool years to adolescence. His model is based on spatial role-taking process. According to Flavell, Level o role-taking is a preoperational process in which the child relies on immediate, given perceptions. The child focuses on end states rather than transactions between individuals. From the ages of approximately 7 to 11 (concrete operational period), the child can decenter and make inferences beyond the information given. There is a movement from the overt and concrete, to the covert and psychological. The child is also able to focus on transactions, and reciprocity develops. By adolescence, the child is accurately able to understand the viewpoint of another in an actual social situation and is also able to conceive the perspective of another in a hypothetical situation.

In addition to these stages, Flavell (1974) and Flavell et. al. (1968) present a model of interpersonal inference based on an information processing approach. This processing approach describes the sequential psychological events in a single act of role-taking. In the first event, the individual must be aware that another child has covert, psychological experiences; the individual must be aware of their existence. Then, the child must recognize that the present situation needs some inference about another's psychological state. Inference refers to any of the child's mental activities that result in a representation of another person's 
subjective experiences. Finally, application is any subsequent behavior of the child as a consequence of the inference, e.g., accommodating one's message to a particular listener about whom one has just made an inference. Empirical Research

Research on the models of role-taking and the tenets they embody has gerierally been supportive. The sequential developmental levels of role-taking have been found to increase with age (Flavell, et. al., 1968; Ford, 1979), and the Piagetian levels of concrete operations have been found to be essential, but not sufficient, for development of roletaking (Hollos, 1975; Hollos \& Cowan, 1973). However, Piaget's (1970) assumption that role-taking is a unitary, organized way of reasoning about the world has not received strong empirical support. This has cast some doubt on the validity of the role-taking construct, and the evidence for this needs to be examined.

Rubin (1973) studied the question of role-taking being an organized, unitary ability by testing 80 children from kindergarten to sixth grade on a battery of tests designed to assess the ability to take another's role. These tests were a spatial role-taking task and three cognitive roletaking tasks. In addition, there were measures of verbal intelligence, conservation, and popularity. The role-taking tasks,with mental age partialled out, correlated significantly, but moderately $(\underline{r}=.31-.36)$. A factor analysis revealed a principle factor defined by all measures of 
role-taking and conservation. This factor accounted for only $57 \%$ of the total variance. The second factor represented entirely the popularity variable.

Kurdek (1977), in a similar manner, reasoned that if role-taking is a unitary ability, then a child's ability for each of the role-taking processes (Shantz, 1975) should be the same, and equally predict later role-taking development. If, however, role-taking in each of these areas (affective, cognitive, spatial) involves different composites of abilities, then different relationships from what is predicted above should be found. Using kindergarten through third grade children and a stepwise multiple-regression analysis procedure, Kurdek found little support for conceptualizing role-taking as a unitary ability. However, the pattern of relationships obtained was not readily interpretable.

In an earlier study, Turnure (1975) attempted to examine the interrelationships between role-taking, cognitive development, and other factors like sex and intelligence. Using boys and girls of three age levels $(7,9$, and 12 years), matched for intelligence, Turnure administered Feffer's role taking task (Feffer \& Gourevitch, 1960) and two Piagetian tasks (Floating objects and Balance Beam). The results indicated that performance on all tasks generally increased with age, but correlations between performance on the two types of tasks were generally not significant. Turnure concluded that the ability to decenter and possibly 
role-take is not a simple, unitary phenomenon, and that there are a number of subtle, but important age and task differences. There are several other studies which have intercorrelated two or more different role-taking tasks and found no significant relationships (Finley, French \& Cowan, Note 4; Rothbaum, Note 5; Sullivan \& Hunt, 1967). Piche, Michlin and Rubin (1975) concluded that role-taking is a complex social psychological process, entailing several subskills which may develop differently, and that the tasks which purport to measure role-taking as a whole may simply reflect some subset of component abilities.

In cross cultural studies (Hollos, 1975; Hollos \& Cowan, 1973) comparing the development of logical operations and role-taking ability in three social settings, factor analysis yielded two main factors - a conservation factor and a roletaking factor. In addition to not finding any significant relationship between role-taking and logical operations tasks, Hollos (1975) concluded that role-taking appears to be made of two separable components. Hollos called these a verbal component and a spatial-concrete component. Hollos stated that just as there are different aspects to conservation tasks, the same appears to be true for role-taking tasks.

These studies suggest that there is, at best, only a moderate relationship among various role-taking tasks. Some studies have found significant correlations and others have not. The reasons for this remain unclear, but there 
are several possibilities. The magnitude of correlations among tasks can be influenced by the reliability of each task, the range of scores, and the difficulty level of each task. Thus, low intercorrelations might be statistical artifacts, or one or more of the tasks do not measure roletaking. It may also be they do measure role-taking, and it is not a general ability or unitary construct. Theoretical Analysis

In an excellent review of the literature, Higgins (1981) assumes the perspective that role-taking may not be a unitary construct. He illuminates what might be some of the underlying component abilities of role-taking. Higgins lists four possible theoretical dimensions of role-taking: a) independence from stimulus input, b) content of judgments, c) interrelating multiple elements, and d) controlling the self. These are assumed to be the abilities or skills that contribute to the development of role-taking behavior.

Independence from stimulus input. This refers to going beyond the information given in making judgments of another. The judgment of another is an inference about, rather than just a description of, another person. Role-taking is a process whereby one determines certain attributes of another person, and with development, the attributes become primarily inferential rather than directly perceptible (Flavell et. al., 1968; Flavell, 1974). However, it is difficult to know in many cases whether or not a judgment involves an inference. For example, when someone observes another person crying and 
judges that person to be upset, it is unclear whether inference is involved. For this reason, this dimension is difficult to assess both clinically and empirically.

Content of judgments. Just as the judgments develop from the directly perceptible to the inferential, so the contents of these judgments proceed from the concrete to the abstract. Miller, Kessel and Flavell (1970) suggest that one aspect of role-taking development is the development from a consideration of other's actions to a consideration of another's thoughts. Judgments increase in complexity and become more psychological (Livesly \& Bromley, 1973; Peevers \& Secord, 1973). However, as Higgins (198I) points out, a general developmental change in the contents of the judgment does not necessarily reflect a developmental change in the process of role-taking, i.e. how the judgment is derived. Therefore, one should focus on the nature of the judgmental process and not the contents of the judgment.

Interrelating multiple elements. The nature of the roletaking process appears to involve an increase in the number of mental elements considered, and the interrelationship among them. Piaget and Inhelder (1969) state that social exchanges go from a state of relative lack of coordination between a child's point of view and that of others, to a state of coordination between points of view. Decentering is the prerequisite ability not only for the formation of cognitive operations in the physical universe, but for cognitive operations in the interpersonal and social universe. 
Decentering allows one to consider more than one aspect (element) of a situation as well as their interrelationship. Flavell et. al. (1968) and Miller et. al. (1970) postulate the development of role-taking from responses to another person's characteristics (a minimum of one mental element), to responses that includes another person's responses and characteristics (a minimum of two mental elements) etc. In a similar manner, Selman's model of role-taking features a progressive increase in the number of elements and relations that must be kept in mind (Higgins, 1981). Level 0 role-taking is that children cannot relate self and other's perspectives. From there, the child progresses to Level 1 where there is the realization that other's perspectives may be different from one's own (one mental element). Level 2 role-taking is the ability to reflect on the self from another's viewpoint (a minimum of two mental elements). Level 3 role-taking is the ability to step outside of a relationship and simultaneously coordinate the perspective of each (a minimum of three mental elements).

It is also possible to conceptualize Feffer's (1970) three levels of role-taking in terms of a progressive increase in the number of mental elements considered. At the initial level, the subject has only to be aware of one person and does not have to coordinate with person two, and thus only one mental element is considered. At the next higher level, a subject must coordinate person one's response in relation to character two, and thus there are two mental 
elements involved, as well as the coordination of the relation between them. This continues until all person's viewpoints are considered as well as their interrelationships.

The interrelating of multiple elements is also seen in other areas of social cognition. Aboud (1981), in studying kindergarten through second grade children, concluded that the major development in conflict resolution after age five is the ability to differentiate and combine the outcome of two processes: validity of information and subjective preferences. In a study of achievement related predictions (Kun, Parsons, \& Ruble, 1974), it was found that six year olds used ability and effort information in making their judgments of performance. However, 10 year olds and adults considered not only the independent values of effort and ability, but also the relationship between them. Thus, it appears that interrelating multiple elements may be a general component ability underlying several areas of social cognitive development, and, in particular, may be an important factor in role-taking operations.

Controlling the self. The last underlying dimension regarding role-taking development, as put forth by Higgins (1981), is controlling the self. Controlling the self can vary in difficulty from recognizing that another person may have a different view than oneself because the person is in a different circumstance, to where the person may have a different view even though the person is in the same circumstance. Children become progressively better at preventing 
their viewpoint from interfering with their judgments of another person's viewpoint. Role-taking tasks may vary as to the degree of difficulty in controlling the self (Higgins, 1976). Piaget's three mountain task (Piaget \& Inhelder, 1956), for example, requires that the subject view a scale model of three mountains and imagine the mountains' appearance from the viewpoint of another person whose position is different from the subject's own. This task requires that the subject recognize that the target person has a different view only because the person is in a different circumstance. In a similar manner, Kraus and Glucksberg's (1967) referential communication task requires the speaker to describe each stimulus array so that the listener can select the same stimulus from among an identical array of stimuli. This task, too, requires that the subject understand that the listener has a different view only because the person is in a different circumstance. The task can be solved by the child asking, "What information does the listener need, so that he or she can see the array from my perspective and select the correct item?" (Higgins, 1981).

In contrast, a measure like Flavell et. al.'s (1968) communication task IIA requires that the child recognize that the other person may have a different view, even though the person is in the same circumstance. In this task, the child has to tell a story to a younger child so that the child can understand it, thus requiring the child to take into account that the younger child's abilities are different 
from his or her own. In essence, the child must control his or her viewpoint in the presence of another person in the same situation, in order to understand the viewpoint of the other. It is suggested that there is a progressive development, in terms of task difficulty, from controlling the self under different situations to controlling the self in the same situation.

\section{Summary}

Role-taking models, and in particular the two most extensively developed models, adhere to certain assumptions regarding the role-taking construct. One of these assumptions is that role taking is a unitary, organized way of reasoning about the social world. However, evidence for this assumption has been lacking from empirical studies. Recent trends in the role-taking literature strongly indicate roletaking is not a unitary ability, but an ability made of component skills (Hollos, 1975; Kurdek, 1977; Piche, Michlin \& Rubin, 1975). Higgins (1981) outlines four possible theoretical dimensions or component abilities of role-taking: content of judgments, independence from stimulus input, interrelating multiple elements, and controlling the self. The latter three abilities appear to be more related to the process of role-taking, and, therefore, possess greater utility in understanding the construct, and applying it to actual social situations. However, independence from stimulus input is difficult to empirically assess and utilize socially with present methodology. The ability to interrelate 
multiple elements is similar to, or another manifestation of, Piaget's construct of decentration, and may be its social parallel. Iike decentration, it may be a continuous dimension involving the ability to analyze transformations and also, like decentering, it may be a prerequisite skill for other cognitive abilities. The ability to control the self from intruding or dominating one's judgment of others, may reflect a development away from an embeddedness in one's point of view, and suggests that role-taking also involves a continuous dimension of controlling the self under increasing conditions of involving the self.

The distinction between these last two component abilities may be valuable when comparing different role-taking tasks, because the principle requirements of each task may be different (Higgins, 1981; Kurdek, 1977). It could be that differences among role-taking tasks are whether the principle requirement is interrelating multiple elements or controlling the self. This conceptual difference may also account for the relatively weak and inconsistent correlations found in studies comparing role-taking tasks (Chandler, 1978; Glucksberg, Krauss \& Higgins, 1975; Shantz, 1975). Lastly, viewing role-taking as a composite of these abilities, rather than a unitary ability, may clarify some of the confusion surrounding the development of this construct and its relationship to social behavior at different ages. 
Role-Taking and Social Behavior

A review of the literature indicates that many of the child's social behaviors may be learned within the context of the peer culture (French \& Tyne, 1982). Feers, for example, promote social skill development by providing children with access to play groups (Corsaro, 1981), which function to instruct the child in the management of aggressive and sexual relations (Fine, 1981; Hartup, 1978), and other numerous social, physical, and cognitive skills (Fine, 1979). The peer group also provides emotional functions by giving children security and support in various situations (Freud \& Dann, 1951; Ispa, Note 6).

Given these functions of social relations, researchers' and clinicians' concerns are raised because a considerable number of children lack friends in school. A study by Hymel and Asher (Note 7) reported that 11\% of the children studied were not chosen as a friend and another $22 \%$ were only chosen once. These unpopular children have been found to be low achievers (Bonney, 1971), to experience learning difficulties (Amidon \& Hoffman, 1966), and to drop out of school (Barclay, 1966; Ullman, 1957). In addition, low social acceptance has been an indicator of adolescent delinquency (Roff, Sells \& Golden, 1972), later representation on an adult psychiatric register (Cowen, Pederson, Babigian, Izzo \& Trost, 1972), bad conduct discharges from the military (Roff, 1961) and adult suicide (Stengel, 1971). 
The study of the relationship between social-cognition and peer relationship difficulties appears to be a viable area of research, as role-taking can provide us with a conceptual understanding of children's social behaviors, and link both theory and practice. Role-taking has been postulated by many theorists to be a necessary ingredient in adequate social functioning (Chandler, 1973; Chandler, Grenspan \& Barenboim, 1974; Feffer, 1970; Feffer \& Suchatliff, 1966; Kohlberg, 1969; Piaget, 1965; Selman \& Byrne, 1974). Research has shown it to be positively correlated with a predisposition to cooperate (Johnson, 1975), generosity (Rubin \& Schneider, 1973), and altruistic behavior. (Buckley, Siegal \& Ness, 1979) in preschoolers. It still remains to be seen if this is true for elementary age students. Conversely, developmental delays in the acquisition of role-taking ability have been ascribed to various populations experiencing social adjustment problems, including the mentally retarded (DeVries, 1970), autistic and schizophrenic children (Feffer \& Gourevitch, 1960), children of psychotic parents (Straus, Harder \& Chandler, 1980), and behavior disordered children (Chandler, 1973).

This expected relationship between role-taking and social behavior derives from Piaget's theory (1965, 1967). Piaget suggested a bidirectional causal relation: roletaking as a necessary factor for the development of peer interaction and vice versa. Role-taking ability increases as a result of the child's confrontation with peers who 
differ in their thoughts, needs, wishes, and feelings. As role-taking ability emerges, the child can begin to engage in reciprocal social behavior which, in turn, should lead to increased peer acceptance and popularity (Piaget, 1932/ 1965).

Although it is documented that role-taking is related to children experiencing social adjustment problems, the relationship to social acceptance in normal elementary age children is uncertain (Shantz, 1975). Rubin's (1973) and Gottman, Gonso and Rasmussen's (1975) studies have not shown empirical support for the relationship between conventional measures of role-taking and popularity in elementary school children. Other studies, however, support a relationship between role-taking and social acceptance. Burka and Glenwick (1978); using fourth grade males and females, found that role-taking was correlated with classroom adjustment for boys and girls, but with peer acceptance only for boys. There were also sex differences in the pattem of role-taking and actual behavior, with low role-taking ability associated with shy, anxious behavior for girls and acting-out behavior for boys. In another study, using fourth and fifth grade males, role-taking was found to differ among sociometric groups of popular, average, neglected, isolated, and rejected children (Geary, Note 2). The popular children were found to be superior on the role-taking task, with the rejected and isolated children obtaining the lowest scores. 


\section{Intervention Studies}

There have been a number of intervention studies aimed at determining the effects of role-taking on social behavior and peer acceptance. Chandler (1973) divided delinquent adolescents with low role-taking skills into three groups: a training group, placebo group, and a control group. After a ten-week training program, the role-taking skills of the three groups were retested. The trained group showed significant increases in role-taking ability compared to the other groups. In addition, a follow-up 18 months later showed that the role-taking trained boys committed approximately half as many known delinquencies as the other groups.

Three studies have attempted to facilitate communication skills by having the child learn to take the role of the listener. Two studies showed minimal changes in communicative ability (Fry, 1966; 1969), and one found significant increase with some generalization (Shantz \& Wilson, 1972). In two studies of spatial role-taking training, positive results were obtained in one study (Iaubengoyer, Note 8) and no effects in the other (Douglas, Note 9).

In studies more related to social acceptance, spivak and Shure (1974) trained children to consider alternative ways of behaving in social problem situations, to be aware of the consequences of their behavior, and to increase their ability to understand others' feelings, thoughts, and intentions. They report improved social problem-solving ability, behavior, and acceptance with such training procedures. 
However, Elardo (Note 10), using a similar training program, found no significant increase in role-taking ability or social acceptance with peers.

Overall, these studies have attempted to demonstrate that role-taking ability can be facilitated and have a causative effect on social behavior and acceptance. However, the results have not been consistent, and further investigation is needed to understand the reasons for the differences among the studies. Covariates of Social Acceptance

Two variables commonly associated with social acceptance are intelligence and socioeconomic status (SES). The relationship between intelligence and social acceptance has been explored in numerous studies (Hartup, 1970). Correlations between IQ and popularity are usually significant, although they may range from relatively low magnitudes (.20) to moderate levels (.65) (Barbe, 1954; Bonney, 1944; Davis, 1957; Gallagher, 1958b; Hill, 1963). Overall, studies have generally indicated that intellectually gifted children are likely to be more popular than their less gifted peers (Gallagher, 1958A; Miller, 1956). Conversely, the mentally retarded, in regular classrooms, are likely to be less popular than other children (Baldwin, 1958; Johnson, 1950; Kirk, 1964).

One problem with the above studies is that the correlations between IQ and popularity are computed without taking into account the variance due to socioeconomic status. Since 
IQ and SES are directly related, it is not clear whether IQ or SES actually accounts for a significant portion of the variance in children's popularity (Hartup, 1970). Sells and Roff (Note 1l) tried to answer this question in a study using a sample of children from Minnesota and Texas. The Minnesota sample $(\mathrm{N}=2,800)$ was divided into four SES groups, and the IQ of popular and nonpopular children were compared. Popular children were found to be significantly brighter (12-20 points) than nonpopular children within all four SES levels. In the Texas group $(\mathrm{N}=3,216)$, children were sampled from schools serving homogeneous SES populations of either working-class or middle-class children. Correlations between IQ and popularity were .22 for the working-class group and -39 for the middle-class group. Unfortunately, Sells and Roff did not compute the correlations between SES and social acceptance.

Generally, research supports the conclusion that lowerclass children are less popular in mixed peer groups than middle or upper class children (Hartup, 1970). For example, Cannon (1957) and Elkins (1958) both report a direct relationship between popularity and SES, but the effects of IQ were not partialled out. Grossman and Wrighter (1948) included IQ as an independent variable and sampled 6th grade students from three IQ levels. It was found that the higher the SES level, according to the father's occupation, the more popular the child at each IQ level. There is also some evidence for a sex difference between SES and social 
acceptance. Studies have found that SES is a better predictor of girl's peer acceptance than boy's peer acceptance (Brown \& Bond, 1955; Davis, 1957).

Overall, these studies indicate that both IQ and SES are related to social acceptance. The magnitude of the relationship of these factors to social acceptance varies considerably among studies, but the relationships do exist so they cannot be easily dismissed. Thus, in terms of roletaking abilities, SES and IQ may substantially influence the relationship between interrelating multiple elements, controlling the self, and social acceptance. This needs to be empirically investigated.

\section{Summary}

Researchers and clinicians are concerned with the considerable number of children who are not accepted by their peer group. These unpopular children have been found to experience a wide range of educational and emotional difficulties. Developmental delays in role-taking ability have been ascribed to various populations experiencing severe social adjustment problems, including the mentally retarded and behavior disordered children. However, the relationship between role-taking ability and social acceptance in normal elementary age children has been equivocal in both correlational and intervention studies.

The equivocal findings may be due to the way the roletaking construct has always been seen, as a unitary ability. If role-taking is instead composed of two or more abilities, 
each of these may correspond to some appropriate behaviors at different ages, and to different levels of social acceptance at those ages. For example, it may be that isolated children develop the ability to interrelate multiple elements relatively quickly, but lag behind in their ability to control the self or vice versa. In addition, it has been demonstrated that IQ and SES are also related to social acceptance. These factors need to be included in any investigation of role-taking and social acceptance, to obtain a clearer understanding of the contribution of role-taking to popularity. 
Rationale and Hypotheses

\section{Rationale}

This research project is designed to examine the roletaking construct and the relationship between role-taking ability and social acceptance in elementary school students. Role-taking is traditionally viewed as a unitary ability that increases with age and is related to social acceptance. However, the evidence reviewed here casts serious doubts on the validity of the role-taking construct as it is traditionally viewed. The evidence suggests that role-taking is a multi-faceted construct, composed of two or more abilities. Two possible underlying abilities reviewed here are interrelating multiple elements, like the viewpoints of person one and two, and controlling the self. There is a need, therefore, to examine the development of each of the se abilities separately. In addition, the proposition of separate subskills or abilities may be important in clarifying why low correlations have been found among role-taking tasks.

Distinguishing between the ability to interrelate multiple elements and controlling the self has applied, as well as theoretical implications. It may be that the pattern of development differs substantially between these two abilities, and thereby influences social behavior differently at each age level, and which ultimately relates to a child's social acceptance (See Figure 1). For example, children may 


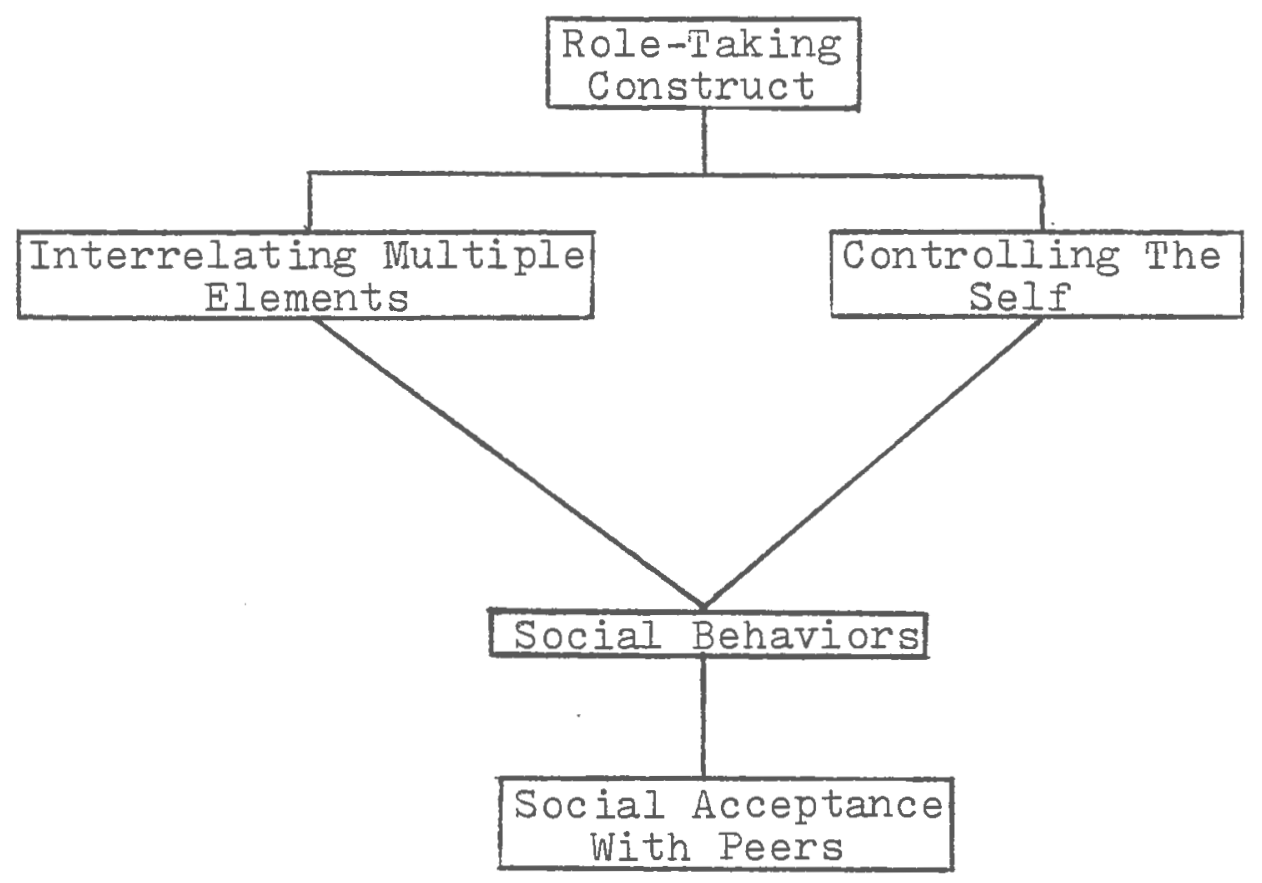

Figure 1. Role-Taking and Social Acceptance 
be popular at one age level because of the ability to quickly interrelate multiple elements, but at another age level, controlling the self may be the critical ability. This needs to be investigated for a more thorough understanding of the role-taking construct and its relationship to social acceptance among peers.

Hypotheses and Predictions

The first question addressed by this study is whether or not role-taking is a unitary construct or a construct composed of two component abilities.

First hypothesis. It is hypothesized that role-taking is not a unitary construct and is composed of separate component abilities which have been previously identified as interrelating multiple elements and controlling the self. This hypothesis leads to the following prediction about the role-taking construct:

1. It is predicted that if role-taking is a unitary construct, then the correlation between the tasks measuring interrelating multiple elements and controlling the self will be significant.

The second area addressed by the research project is that the component abilities of role-taking develop differentially among normal elementary school children.

Second hypothesis. It is hypothesized that each of the component abilities of role-taking do not develop simultaneously among children from early to middle elementary grade levels. This hypothesis leads to the following predictions about the development of role-taking abilities. 
1. It is predicted that there will be a difference by grade level in: a) the ability to interrelate multiple elements and b) the performance on a task measuring controlling the self.

2. It is predicted that performance on a task measuring interrelating multiple elements will be: a) successfully performed by a majority of children in the second grade and b) show a large increase in scores from the second to fourth grade levels, and a small increase from the fourth to sixth grade levels.

3. It is predicted that performance on a task measuring controlling the self will be: a) unsuccessfully performed by second grade children and b) show a small increase from the second to fourth grade levels, and a large increase from the fourth to sixth grade levels.

The third area addressed by this study is the relationship of these component abilities of role-taking to social acceptance among the peer group.

Third hypothesis. It is hypothesized that role-taking abilities will account for a larger share of the variance in social acceptance than either socioeconomic status or intelligence. This hypothesis leads to the following predictions about the contributions of these component abilities to social acceptance:

1. It is predicted that performance on role-taking tasks measuring interrelating multiple elements and controlling the self will: a) contribute to different proportions of the variance on measures of social acceptance by peers.

2. It is predicted that there will be a difference among social acceptance categories in: a) SES of students, b) intelligence levels of students.

3. It is predicted that there will be interaction effects among the attribute variables on: a) SES, b) intelligence, c) interrelating multiple elements, and d) controlling the self.

4. It is predicted that the more effective role-takers will: a) score higher on social acceptance among their peers. 
Method

\section{Subjects}

Ninety $(N=90)$ students were selected from grades 2,4 , and 6 at an elementary and junior high school in southern New England. These 90 students were, through stratified random sampling, chosen from a larger population of 314 students. More specifically, five male and five female students were chosen from each of three social acceptance categories at each grade level; popular, isolated, rejected, for a total of 45 male and 45 female students. Further, the subjects were classified according to SES level by educational and occupational status of parents. There were 16 students (18\%) in the upper class; 60 students (66\%) in the middle class; and 14 students (16\%) in the lower class. The town in this study is located in souther New England and has a population of approximately 35,000 and a large working and professional class distribution (1980 census and city hall report). There were relatively equal numbers of working class and professional class families.

Parental consent for the sample was obtained through a letter informing them of the project and asking for their written permission (see Appendix A). Eighty-four percent of the parents sampled gave permission for their child to participate in the study. The consent from students was obtained verbally. Student confidentiality was maintained through the use of numbers to code each answer form. Further, 
all procedures for subject sampling were negotiated with the superintendent of school's office and with the principals of the elementary school and junior high school. Once the negotiations were completed, administration of the social acceptance measures began. Data were obtained on all children in the classrooms except those in special education populations, i.e. mentally retarded, learning disabled, and emotionally disturbed. These children were excluded because their lack of social acceptance and low role-taking ability has been previously established (e.g. DeVries, 1970).

The sample of students used for the present study is representative of the elementary school and junior high school population, and there is no reason to believe that any preselection criteria have biased the sample. Attribute Variables

Social acceptance. This variable was measured in two ways, peer nominations and teacher ratings. Administration of the peer nomination and teacher rating scales took place during a classroom period, for each class involved.

1. Peer nominations. In the peer nomination procedure, both positive and negative nominations were employed. Positive nominations were obtained by asking, "Name three children you would most like to play with." Negative nominations were gathered by requesting each child to write down three children, "You would not like to play with."1 
The positive nominations were used as a measure of social acceptance, or the extent to which a child is positively valued as a peer. The negative nominations were used as a measure of peer rejection or low social acceptance. In addition to this standard peer nomination procedure, the students were asked to nominate peers for the isolate category. Specifically, they were asked, "Name three children in your class who don't like to play with anybody."

The scores each child obtained were the number of positive and negative nominations the child received from his or her same sex peers. ${ }^{2}$ In addition, there was a third score, which was the number of isolate nominations a child received. Therefore, each child has three possible scores, with the range of scores dependent upon the number of same sex peers in the classroom.

$1_{\text {Weighted measures }}$ were not used on the nomination scales for two reasons: I) Predictive validity has been established only for unweighted sociometric data, e.g. Cowen et. al., 1972. 2) The weighted data contribute little new information and they require the assumption that the child's first acceptance choice is the better friend and that the first rejection choice is the greater enemy. Since this was not part of the instructions, this assumption may not be necessarily valid (Gottman, 1977).

${ }^{2}$ Same sex nominations were used to categorize students into social acceptance groups due to possible sex bias given to members of the opposite sex. Previous sociometric studies have consistently found that both sexes are biased in their attraction for same sex peers and negative in their evaluation of opposite sex peers (Bonney, 1954; Bradley \& Newhouse, 1975; Gronlund, 1953; Novak, 1975; Singleton \& Asher, 1977; St. John, 1975; Tyne \& Geary, 1980). 
The reliability of the peer nomination procedure varies according to the use of positive or negative nominations, and the population sampled, elementary or pre-school. Asher, Singleton, Tinsley and Hymel (1979) sampled 19 four year olds and found test-retest correlations to be .56 for positive nominations, and .42 for negative nominations over a four-week period. Test-retest correlations for elementary school children have been somewhat higher: .84 for positive nominations and .68 for negative nominations over an eightweek period (Bush, Ford \& Schulman, 1973). These nominations have proven valuable in longitudinal mental health studies in identifying future mental health problems (Cowen et. al., 1972; Roff et. al., 1972). They also have concurrent validity with teacher judgments and observations of positive and negative peer interactions (Asher \& Hymel, in press; Hartup, 1970).

2. Teacher nominations. Teachers were asked to indicate what category each child in the classroom could be classified in: popular, isolated, or rejected. A description of each of these groups was provided for every classroom teacher to facilitate this identification process (see Appendix B). Although reliability of teacher nominations has not been well investigated, there is evidence to suggest that teacher judgments are a convenient and valid means of identifying children with social acceptance problems. Green, Forehand, Beck and Vosk (1980) found significant concurrent validity with peer judgments of those who are liked and 
disliked. Using 116 third graders and their teachers, they found peer acceptance and teacher's estimate of average rating given to child by other children to be .44 , and for peer rejection to be .49 . Childers and Matuseak (1972) found predictive validity with pre-school and kindergarten teachers' rating 378 children on social adjustment and achievement. They found correlations of .3I and .5I for pre-school and kindergarten teachers' ratings of social adjustment, respectively. They also obtained a correlation of .87 for kindergarten teachers' ratings of first grade achievement. In another study, using 187 students, teachers' ratings of student peer relationships at age nine was predictive of adult mental health at age 21 (Janes \& Hesselbrock, 1977). In addition, O'Connor (1969) found teachers to be particularly suited for the identification of withdrawn or isolated children, which peer nominations typically do not provide.

It is the combination of peer nominations and teacher nominations that was to be used to classify children into social acceptance categories. The criteria for this classification were as follows:

1. Rejected. These are children who received one or no positive nominations and several negative nominations from their peers, and who received a teacher rating as being rejected by his or her peers.

2. Isolated. These are students who appeared to the teacher to be withdrawn and to interact very little with 
their classmates. They also received no positive or negative nominations from their same sex peers, and have one or more isolate nominations.

3. Popular. These are the children who had the greatest number of positive nominations, one or no negative nominations from their same sex peers, and received a teacher nomination as being popular among the students.

Grade. This attribute variable has three levels. Students were selected from second, fourth, and sixth grade classrooms. These classrooms were from a cluster of two elementary schools and a junior high school.

Sex. An equal number of male and female students were used. Even though previous studies have failed to establish the existence of sex differences on role-taking tasks (Burka \& Glenwick, 1978; Chandler et. al., 1974; Flavell et. al., 1968; Turnure, 1975), the possibility of sex difference was examined with the implication that sex, as a factor, could be collapsed if no differences were found.

\section{Correlates}

Role-taking. Two role-taking tasks were utilized to provide for the measurement of each of the hypothetical component abilities of this construct. Specifically, roletaking performances included: the ability to interrelate multiple elements, and the ability to control the self.

I. Interrelating multiple elements. This construct was operationally defined as the ability to coordinate the relationship between two or more personal perspectives in a 
social situation, where none of the perspectives is that of the observer. This construct was assessed with Feffer's role-taking task (Feffer, 1959; Schnall \& Feffer, Note 12). This study utilized a standardized procedure, that presents two pictures of three characters in a social situation to the subject. After completing the initial story, the student is asked to retell the story from the point of view of each of the characters, that is, to take in turn the role of each person. The two pictures used were card 2 of the Thematic Apperception Test (TAT) (Niurray, 1943) and card 5 of the Education Apperception Test (EAT) (Thompson \& Sones, 1973). Card 2 of the TAT can be described as a country scene: In the foreground is a young woman with books in her hand. In the background a man is working in the fields, and an older woman is leaning against the tree. Card 5 of the EAT is a family scene: Father and mother are looking at a card. The little girl is standing behind her parents and looking at the card.

Performance was evaluated in terms of the child's ability to refocus from character A's point of view to character $B$ in a way that is continuous and interrelated (Schnall \& Feffer, Note 12). Subjects' responses were classified into four categories reflecting the degree to which they were able to refocus from the initial story and interrelate the differing perspectives of the other story characters: a) simple refocusing, b) character elaboration, c) perspective elaboration, and d) change of perspective. 
In order to obtain the greatest differentiation on this task, responses (three per scene) were further analyzed into the 20 subcategories outlined in the manual. Finally, every subject was assigned a score for each picture, based on the scores of his or her three role-taking attempts (range 0 to 60). The scores for each picture were then averaged so that each story contributed equal weight to the combined role-taking score.

To accomplish this scoring method, two scorers were trained by the experimenter. An inter-rater reliability estimate was established using 15 pieces of data randomly selected from the sample of 90 . The 15 subject responses selected comprised a total of 144 scorable problems, to be scored separately by each rater, with the total role-taking score for each story to be used to estimate inter-rater reliability (Winer, 1971). The resulting Pearson productmoment coefficient was .97 ( $\underline{p}<.001)$. The remaining stories were divided randomly between each rater for scoring and the data used as a continuous variable in the analysis.

Feffer's task has demonstrated inter-rater reliability coefficients of .89 , with an $\mathrm{N}$ of 68 (Feffer \& Gourevitch, 1960) to .97 with an $N$ of 60 (Turnure, 1975). A testretest reliability coefficient of .60 ( $N=68$ ) (Narsh, 1981), and a coefficient of .40 was found for subjects' scores on their first and second picture $(\mathrm{N}=60)$ (Turnure, 1975). Validity for the task has been established through several 
studies (Feffer \& Gourevitch, 1960; Marsh, 1981; Schnall \& Feffer, Note 12; Turnure, 1975). These studies report that: 1) according to theory, performance on the task should increase with age, and empirically this has been demonstrated; 2) discriminant validity has been shown by the task's ability to differentiate between those having effective interpersonal relationships and those having interpersonal difficulties.

2. Controlling the self. This construct was operationally defined as the ability to understand the perspective of another person in a social situation that simultaneously involves the perspective of the observer, whereby the observer must control his or her viewpoint in order to accurately reflect the perspective of the other. This construct was assessed with Chandler's role-taking task (Chandler, Note 1; 1972; 1973). The present study used the entire standardized role-taking procedure that presents each student with'six cartoon sequences (see Appendix B). Each of these depicts a central character caught in a chain of psychological cause and effect, such that his subsequent behavior was shaped by and fully comprehensible only in terms of the events which preceded them. Midway into each of these sequences some second character is introduced who, in the role of the late arriving bystander, witnesses the resultant behavior of the central character, but is not privy to the antecedent events which brought them about. Through. this process of information engineering, the subject is placed in a privileged position relative to the story character whose role he is 
later asked to assume. By knowing what information is available to whom, it is possible to specify the degree to which each subject is able to set aside facts known only to himself and adopt a perspective measureably different from his own.

The Chandler role-taking task was scored according to pre-established criteria developed by Chandler (Note 1). A five point scoring system reflecting different levels of potential inability to control the self (range 0 to 4 ) was used to rate each story. The Chandler role-taking score consists of the sum of scores stated for each of the six stories. To accomplish this, two scorers were trained by the experimenter in the Chandler method. Data gathered from a previous study was used for training purposes. Interrater reliability for the present study was estimated using 20 pieces of data randomly selected from the sample of 90 . The 20 pieces of data comprised a total of 120 scorable stories to be scored separately by each rater for use in the computation of the inter-rater reliability coefficient. The resulting Pearson product-moment coefficient was .95 $(\underline{p}<.001)$. The results were used as a continuous variable in the data analysis.

Chandler's role-taking task has extensive reliability and validity data (Chandler, Note 1; Chandler, 1972, 1973; Chandler et. al., 1974; Burka \& Glenwick, 1978; Geary, Note 2). Reliability on Chandler's task has been demonstrated to be superior to most role-taking instruments. Inter-rater 
reliability estimates were .96 and .94 for delinquent and non-delinquent students $(\mathrm{N}=90)$ (Chandler, 1973). Dividing the series of cartoon sequences into two equivalent subsets has yielded a spearman-Brown split-half reliability estimate of .92 ( $N=75)$ (Chandler et. al., 1974). Test-retest reliability has been demonstrated to be .84 over a four-week period, and alternate form reliability is .9l for a sample of 75 (Chandler et. al., 1974). Discriminant construct validity has been shown by the task's ability to differentiate between normal and emotionally disturbed children and adolescents (Chandler, 1972). Construct validity has also been demonstrated by the increase in scores with age (Chandler, Note I).

Intelligence. This construct was assessed due to the fact that previous investigations have found intellectual functioning to be an important factor in social acceptance (Schmuck \& Schmuck, 1975). In order to separate out the contribution of intelligence from role-taking in social acceptance, intelligence was measured with the Ammons Quick Test (Ammons \& Ammons, 1962).

The Ammons Quick Test (QT) is a brief intelligence test based on vocabulary definitions. The student is presented with a plate of four drawings and asked to point to a drawing depending on the word given by the experimenter. Administration and scoring of the test was performed by the experimenter according to the pre-established criteria contained in the manual. 
Alternate form reliability coefficients reported in the manual range from .60 ( N=53), to .96 ( $N=100)$, and .97 in a more recent study (Vance, Blixt \& Ellis, 1980). Test-retest reliabilities have been reported to be .80 to .89 in three groups of high socioeconomic status children, and from .82 to .85 in three groups of low socioeconomic status children. Concurrent validity with the Full Scale WISC-R is .70, $(\mathrm{N}=140)$ (Paramesh, 1982), and .62 ( $N=47)$ with the StanfordBinet (Joesting \& Joesting, 1971). In addition, the QT has been found to correlate significantly with word recognition section of the WRAT, .53 $(\mathrm{N}=140)$, and with the Iowa Test of Basic Skills, .63 ( $N=53)$ (Burgess \& Wright, 1962). Predictive validity has been shown by QT scores obtained in grade ten correlating significantly with a measure of educational attainment obtained eight years later, .41 ( $N=1,628)$ (O'Malley \& Bachman, 1976).

Socioeconomic Status. Each student's socioeconomic status was based on the overall SES of the student's parents. This was determined by Hollingshead's Two Factor Index of Social Position (Hollingshead, Note 13). The parents' occupation and education levels were obtained by contacting the parents themselves. When the occupation and education levels between parents differed, the higher relative status for occupation and education was used. The educational and occupational data were then converted into scaled scores (1-7) using criteria established by Hollingshead. Each scaled score was then multiplied by a factor weight; ? for 
occupational level, and 4 for education level. The weights for each factor have been previously determined by Hollingshead through the use of multiple correlation procedures. The total score obtained by adding the two products, education and occupation scale scores, yielded an index of social position (SES) with a range of 11 to 77 .

The SES scores were used as both continuous and categorical variable in the data analyses. The SES scores were divided into five categories previously established by Hollingshead (Hollingshead, Note 13): Group I includes scores 11 to 17; Group II includes scores 18 to 27; Group III includes scores 28 to 43; Group IV includes scores 44 to 60 ; and Group V includes scores 61 to 77 . To establish a three group categorical variable for data analysis, Groups I and II were combined to comprise the upper class (scores 11-27); Groups III and IV comprised the middle class (scores 28-60); and Group V was the lower class (scores 61-77). Thus, SES will be divided into upper, middle, and lower classes for inter-group comparisons.

\section{Procedures}

The peer nomination, teacher ratings, and role-taking tasks were administered during the spring of 1983. Administration of the peer nomination and teacher rating scale took place during a classroom period as a group procedure. After the completion of these procedures, students were categorized and then randomly selected from each sociometric group (popular, isolated, rejected) until there were 5 male 
and 5 female students for each group at each grade level. These children were told that they had been chosen to participate in a study to find out how children relate to each other and make friends. Parental permission was elicited from their parents in a letter informing them of the project and asking for their written permission. Student confidentiality was maintained through the use of numbers to code each answer form. These students were then given the role-taking and intelligence tests on an individual basis by either the experimenter and/or trained research assistant. The administration of the tasks was counter-balanced to prevent any order or sequencing effect. All student responses were tape recorded verbatim and later transcribed onto paper. Except for the SES measure, the correlate measures were obtained individually from each subject during a 30 minute session. The SES information was obtained by phone from the parents who agreed to let their children participate in the study.

The scorers rated both role-taking tasks and were blind to what sociometric group or grade level the subject was in. Students, teachers, and parents were thanked for their participation in the project. The results of the study will be presented to the school administration, teachers, and parents in the fall of 1983. 
Results

The data generated from this study were examined in two different ways. First, the hypotheses that: 1) roletaking is not a unitary construct and composed of component abilities and 2) these component abilities develop differently among elementary school children, were examined with ANOVA, MANOVA, and correlational statistical procedures. Second, the correlate measures used in the previous analyses then became predictor variables in a discriminant function analysis as a test of the third hypothesis: that there is a differential relative contribution of these component abilities to social acceptance.

Means and standard deviations were calculated for all continuous variables. Significant $\mathrm{F}$ scores were tested for homogeneity of variance using Cochran's $\underline{\mathrm{C}}$ test. Cochran's $\underline{C}$ test was used instead of the more common Hartley $\underline{F} \max$ procedure, because Cochran's $\underline{C}$ test uses more information from the sample data and is thus generally more sensitive than the Hartley test (Winer, 1971). No violations of homogeneity of variance were found using a probability level of $\underline{p}<.01$ (see Table 12 Appendix $\dot{\mathrm{C}}$ ). In a similar manner, no violations of homogeneity of dispersion matrices were found for the MANOVA procedure using a $\underline{p}<.01$. The attribute variables of sex, grade level, and social acceptance were then examined for their relationship with each of the correlate measures; Chandler's role-taking task, Feffer's 
role-taking task, SES, and IQ, using a three-way MANOVA and a series of three-way ANOVAs. All significant $\underline{E}$ scores were further analyzed with either a simple effects test (for interaction effects), a Tukey HSD test for main effects, or discriminant function analysis as a follow-up to MANOVA. A probability level of $\underline{p}<.05$ was used for all statistical tests.

The relationship among the dependent measures was also examined using a correlation matrix. These dependent measures were then used as predictor variables in a multivariate discriminant function analysis to determine the contribution of the role-taking tasks and the demographic variables to social acceptance. All analyses, except for the simple effects test and Tukey HSD, were calculated with the SPSS-X computer program (SPSS-X, 1983). Analysis of the Role-Taking Construct

To test the first hypothesis, and its subsequent prediction, that the correlation between the role-taking tasks be significant if there is a unitary construct, pearson product-moment correlations were computed. In addition to the correlation between the tasks measuring interrelating multiple elements (Feffer's role-taking task) and controlling the self (Chandler's role-taking task), correlations were also computed between these measures and the continuous variables of IQ and SES (see Table 2). Specifically, Chandler's role-taking task was significantly related to Feffer's role-taking task, $\underline{r}=-.28, \underline{p}<.01$, and IQ, $r=-.34$, 
$\underline{p}$ <.01: These correlations indicate a significant relationship between the component abilities of role-taking, and that the measure of controlling the self (Chandler's task) is significantly related to intelligence. However, when the correlation coefficients are squared to obtain the proportion of common variance between the measures, the proportion is very low; $\underline{\underline{r}}^{2}=.08$ between Chandler and Feffer's task, and $\underline{r}^{2}=.12$ between Chandler's task and the measure of IQ. Thus, for practical purposes there is little common variance between the se measures.

Table 2

Pearson Product-Moment Correlation Matrix for Role-Taking Tasks and Demographic Variables ( $N=90)$

\begin{tabular}{lcccc} 
Variables & Chandler & Feffer & IQ & SES \\
Chandler & & $-.28^{* *}$ & $-.34^{* *}$ & .18 \\
Feffer & & & .19 & $-.23^{*}$ \\
IQ & & & - & $-.25^{*}$ \\
SES & & & & - \\
\hline
\end{tabular}

$* * p<.05$

Feffer's role-taking task was found to be significantly related to $\operatorname{SES}, \underline{r}=-.23, \underline{p}<.05$, and $I Q$ was also found to relate significantly to SES, $\underline{r}=-.25, \underline{p}<.05$. Thus, it would appear that as socioeconomic status increases (decrease in Hollingshead index) there is an increase in IQ and the ability to interrelate multiple elements. Again, when the correlations are squared to obtain the proportion of common variance between the measures, the proportion is quite low; 
$\underline{r}^{2}=.05$ between Feffer's task and socioeconomic status, $\underline{r}^{2}=.06$ between socioeconomic status and intelligence. Role-Taking Development

To test the second hypothesis and its derived predictions that there would be a difference by grade level in the ability to interrelate multiple elements and controlling the self; and that interrelating multiple elements would be successfully performed at an earlier grade level than controlling the self, a three-way MIANOVA and four three-way ANOVAs were computed. Specifically, a grade by sex by social acceptance MANOVA was computed for the correlate measures of IQ, SES, Chandler's role-taking task, and Feffer's roletaking task simultaneously. The MANOVA was computed since it does not ignore intercorrelations between dependent variables and, unlike univariate tests, takes into consideration the fact that the levels of a given factor are being compared more than once. The grade by sex by social acceptance univariate ANOVAs were computed separately for each correlate variable. In each analysis the sex dimension included male and female groups; the grade dimension included second, fourth, and sixth grade groups; and the social acceptance dimension included popular, isolated, and rejected groups. The analysis of each correlate measure is presented separately, with means and standard deviations given in tabular form ( see Table 13 Appendix C). Since the results of the MANOVA were not different from the ANOVAs and do not add to the understanding of the results, the data from this 
procedure are presented in the appendix rather than the text ( see Table 14 Appendix $\mathrm{C}$ ). The MANOVA may not have been more powerful or sensitive than the ANOVAs since the intercorrelations among the correlate variables were not very large.

Interrelating multiple elements. This factor was measured by Feffer's role-taking task. The only significant effect was the main effect for grades, $F(2,72)=7.32$, $\underline{p}<.001$ ( see Table 3).

Table 3

Summary of ANOVA of Feffer's Role-Taking Test by Grade, Sex, and Social Acceptance

\begin{tabular}{|c|c|c|c|c|c|}
\hline Source & $\underline{S S}$ & $\underline{D F}$ & $\underline{M S}$ & $\underline{F}$ & $\underline{w}^{2}$ \\
\hline Grade. & 621.51 & 2 & 310.75 & $7 \cdot 32 * * *$ & .12 \\
\hline Social Acceptance & 185.61 & 2 & 92.80 & 2.19 & \\
\hline Sex & .07 & 1 & .07 & .01 & \\
\hline $\begin{array}{l}\text { Grade by Social } \\
\text { Acceptance }\end{array}$ & 20.14 & 4 & 5.04 & .12 & \\
\hline Grade by Sex & 65.71 & 2 & 32.85 & .77 & \\
\hline $\begin{array}{l}\text { Social Acceptance } \\
\text { by Sex }\end{array}$ & $247 \cdot 37$ & 2 & 123.69 & 2.91 & \\
\hline $\begin{array}{l}\text { Grade by Social } \\
\text { Acceptance by Sex }\end{array}$ & 106.88 & 4 & 26.72 & .63 & \\
\hline Within Cells & 3058.00 & 72 & & & \\
\hline
\end{tabular}

Follow-up tests of the grade level effect with a Tukey HSD test revealed that the mean Feffer rating for sixth graders ( $\underline{M}=20.14)$ was significantly higher than the second grader $(\underline{M}=13.7), \underline{p}<.01$. There were no significant differences between the second and fourth graders or between 
the fourth and sixth graders. The Tukey HSD procedure was used as a compromise between the very conservative Scheffé and more liberal follow-up tests. The Scheffé procedure is very conservative with respect to type $I$ error, but may fail to yield significant differences when they do, in fact, exist, a type 2 error. In a preliminary investigation of this kind, less conservativeness in making a type $I$ error may be tolerated until constructs and procedures are more refined. The results support the prediction that performance on the roletaking task measuring interrelating multiple elements would differ by grade level. However, the proportion of variance on Feffer's task due to. grades is only 12\%, as calculated by Hays-Omega square.

Controlling the self. This factor was measured by Chandler's role-taking task. The ANOVA indicated a significant main effect for grade level, $\underline{F}(2,72)=20.48, \underline{p}<.001$ and social acceptance, $\underline{F}(2,72)=26.21, \underline{p}<.001$ (see Table 4). The results of main effect for social acceptance will be discussed in a later section.

A Tukey HSD follow-up test for grade level indicated that second grade students $(\underline{M}=16.20)$ had higher mean scores on Chandler's task than either fourth $(\underline{M}=11.50)$ or sixth grade students $(\underline{\mathbb{M}}=9.70)$. There was no significant difference between fourth and sixth grade students. Since Chandler's task correlated significantly with IQ, and intelligence differences were found between grade levels (see Table 6), the pattern of development, for this variable, may be different 
Table 4

Summary of ANOVA of Chandler's Role-Taking Test by Grade, Sex, and Social Acceptance

\begin{tabular}{|c|c|c|c|c|c|}
\hline Source & $\underline{S S}$ & $\underline{D F}$ & $\underline{\mathrm{MS}}$ & $\underline{F}$ & $\underline{\omega}^{2}$ \\
\hline Grade & 675.80 & 2 & 337.90 & $20.48 * * *$ & .22 \\
\hline Sex & .04 & 1 & .04 & .01 & \\
\hline Social Acceptance & 865.07 & 2 & 432.53 & $26.21 * * *$ & .28 \\
\hline $\begin{array}{l}\text { Grade by Social } \\
\text { Acceptance }\end{array}$ & $73 \cdot 33$ & 4 & 18.33 & I.II & \\
\hline Grade by Sex & 70.82 & 2 & 35.41 & 2.15 & \\
\hline $\begin{array}{l}\text { Social Acceptance } \\
\text { by Sex }\end{array}$ & 23.82 & 2 & 11.91 & .72 & \\
\hline $\begin{array}{l}\text { Grade by Social } \\
\text { Acceptance by Sex }\end{array}$ & 27.51 & 4 & 6.88 & .42 & \\
\hline Within Cells & 1188.00 & 72 & & & \\
\hline
\end{tabular}

with IQ partialled out. An ANCOVA was therefore calculated to partial out the effects of intelligence on controlling the self. The results were, however, the same as found for the ANOVA procedure: Second grade students $(\underline{\mathbb{M}}=15.60)$ had higher mean scores on Chandler's task than either fourth. ( $\underline{\mathbb{N}}=11.81)$ or sixth grade students $(\underline{\mathbb{M}}=9.96)$. No differences were found in the ANCOVA procedure between fourth and sixth grade students. The results clearly support the prediction of grade level differences on a task measuring the ability to control the self, with the second grade students having more difficulty than fourth and sixth grade students in controlling the self.

Overall, the results support the second hypothesis of grade level differences in the ability to interrelate multiple elements and control the self. However, the prediction 
that the ability to interrelate multiple elements would develop earlier than the ability to control the self does not appear to be supported by the test data. Interrelating multiple elements showed a continual increase over grades with the significant difference found between second and sixth graders. Controlling the self manifested a slightly different pattern of development. The increase in this ability was between the second and fourth grades, with no significant increase between the fourth and sixth grade.

Socioeconomic status. This continuous variable was measured with Hollingshead's two-factor index of social position. A significant two-way interaction effect was obtained for social acceptance by sex, F $(2,72)=4.60, \underline{p}<.05$ ( see Table 5), and this will be discussed in a later section. The results give no evidence for SES differences by grade.

Table 5

Summary of ANOVA of SES Results by Grade, Sex, and Social Acceptance

\begin{tabular}{|c|c|c|c|c|}
\hline Source & $\underline{S S}$ & $\underline{\mathrm{DF}}$ & $\underline{\mathrm{NSS}}$ & $\underline{F}$ \\
\hline Grade & 108.02 & 2 & 54.01 & .29 \\
\hline Sex & 352.04 & 1 & 352.04 & 1.94 \\
\hline Social Acceptance & 236.96 & 2 & 118.48 & .65 \\
\hline $\begin{array}{l}\text { Grade by Social } \\
\text { Acceptance }\end{array}$ & 310.38 & 4 & 77.59 & .43 \\
\hline Grade by Sex & 196.29 & 2 & 98.14 & .54 \\
\hline $\begin{array}{l}\text { Social Acceptance } \\
\text { by Sex }\end{array}$ & 1672.96 & 2 & 836.48 & $4.60 *$ \\
\hline $\begin{array}{l}\text { Grade by Social } \\
\text { Acceptance by Sex }\end{array}$ & 467.71 & 4 & 116.93 & .64 \\
\hline Wi.thin Cells & 130.80 .80 & 72 & 1.81 .68 & \\
\hline
\end{tabular}

$* \mathrm{p}<.05$ 
Intelligence. This continuous variable was measured by the Ammon's Quick Test. A significant effect was obtained for grade, $\underline{F}(2,72)=5.94, \underline{p}<.01$ (see Table 6). A Tukey HSD follow-up test found that second graders $(\underline{N}=108.2)$ scored significantly lower on the Ammon's Quick Test than fourth graders, $(\underline{\mathbb{M}}=116.8), \underline{p}<.01$, and sixth graders $(\underline{\mathrm{M}}=116.4), \underline{\mathrm{p}}<.05$.

Table 6

Summary of ANOVA of IQ Results by Grade, Sex, and Social Acceptance

\begin{tabular}{|c|c|c|c|c|c|}
\hline Source & $\underline{\mathrm{SS}}$ & $\underline{\mathrm{DF}}$ & $\underline{\mathrm{MS}}$ & $\underline{F}$ & $\underline{\omega}^{2}$ \\
\hline Grade & 1424.82 & 2 & 712.41 & $5.94 * *$ & .11 \\
\hline Social Acceptance & 53.89 & 2 & 26.94 & .22 & \\
\hline Sex & 1.88 & 1 & 1.88 & .02 & \\
\hline $\begin{array}{l}\text { Grade by Social } \\
\text { Acceptance }\end{array}$ & $85 \cdot 38$ & 4 & $21 \cdot 34$ & .18 & \\
\hline Grade by Sex & 150.96 & 2 & 75.48 & .63 & \\
\hline $\begin{array}{l}\text { Social Acceptance } \\
\text { by Sex }\end{array}$ & 374.69 & 2 & $187 \cdot 34$ & 1.56 & \\
\hline $\begin{array}{l}\text { Grade by Social } \\
\text { Acceptance by Sex }\end{array}$ & 376.18 & 4 & 94.04 & .79 & \\
\hline Within Cells & 8629.20 & 72 & 119.85 & & \\
\hline
\end{tabular}

The IQ differences among grade levels appear due to several second grade students whose IQ were below 100 (none for fourth and sixth grade), thus lowering the average for this grade level. In addition, there were more fourth and sixth grade students with IQ scores above 120 than in the second grade. 
Role-Taking and Social Acceptance

To test the third hypothesis and its derived predictions: that the tasks measuring interrelating multiple elements and controlling the self would contribute to different proportions of the variance on measures of social acceptance; that there would be a difference among social acceptance groups in SES and IQ; and that there would be an interaction between social acceptance, grade, and sex on the correlate measures, a series of factorial ANOVAs, MANOVA, and multiple discriminant function analysis were computed. Specifically, four grade by sex by social acceptance ANOVAs were computed for each correlate measure; Feffer's roletaking, Chandler's role-taking, SES, and IQ. In addition, a three-way MANOVA was computed for all these correlate measures simultaneously (see Table 14 Appendix C). The dimensions for each factor were the same as in the previously presented analyses. The analysis of each correlate measure in this section is presented separately, with the discriminant function analysis reviewed in a later section.

\section{Interrelating multiple elements. This factor, as}

assessed by Feffer's role-taking task, showed no main effect or any interaction for social acceptance (see Table 3). The results lend no support to the prediction that there would be an interaction between social acceptance, grade, and sex on this factor.

Controlling the self. The results of Chandler's roletaking task showed no interaction effects for grade, sex, 
and social acceptance. There was a main effect for social acceptance, $\underline{F}(2,72)=26.21, \underline{p}<.001$ ( see Table 4). A Tukey HSD follow-up test indicated that popular students $(\underline{N}=8.33)$ were more successful at controlling the self than both isolated ( $\underline{\mathbb{M}}=13.27)$ and rejected students $(\underline{\mathbb{M}}=15.80)$, $\underline{p}<.01$ ( see Table 7). Also, isolated students were more successful in controlling the self than rejected students, $\underline{p}<.05$. The results support the prediction that the more socially accepted children would score higher on role-taking than their peers. The overall percent of variance on Chandler's task due to social acceptance was $28 \%$. There was no support for the prediction that there would be an interaction between social acceptance, grade, and sex on this factor.

Table ?

Means and Standard Deviations for Chandler's Role-Taking Task by Social Acceptance ( $N=90$ )

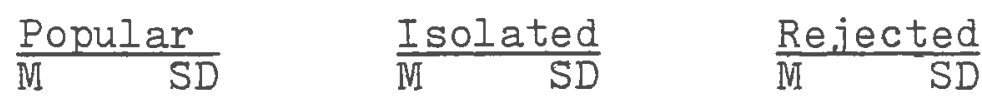

$\begin{array}{lllllll}\text { Combined } & 8.33 & 3.99 & 13.27 & 4.19 & 15.80 & 2.94\end{array}$

Demographic results. SES and IQ were included in the analyses to determine their contribution to the variance in social acceptance and to their relationship with the roletaking tasks in determining a student's social acceptance group. The results for each of these covariates will be presented separately.

1. Socioeconomic status. The SES results indicate no 
main effect for social acceptance, but a significant interaction effect for social acceptance by $\operatorname{sex}, \underline{F}(2,72)=4.60$, $\underline{p}<.05$ (see Table 5). A simple effects test of this interaction indicated that there was a significant difference among female popular, isolated, and rejected students in terms of SES, $\underline{F}(2,72)=3.63, \underline{p}<.05$. Also, there was a significant difference between isolated male and female students in SES level, $\underline{F}(2,72)=9.71, \underline{p}<.01$, with female isolates having a higher socioeconomic status than male isolates (see Table 8). A Tukey HSD follow-up test revealed that in addition to differences between female and male isolates, female isolates had a higher socioeconomic status $(\underline{M}=31.6)$ (lower Hollingshead score) than female popular students $(\underline{\mathrm{M}}=43.8), \underline{\mathrm{p}}<.05$.

The results lend no support to the prediction of a main effect for differences among social acceptance groups on SES. However, the prediction of an interaction between social acceptance and another attribute variable (sex) was supported.

$$
\text { Table } 8
$$

Means and Standard Deviations for SES by Sex and Social Acceptance $(\mathrm{N}=90)$

\begin{tabular}{lccccccc}
\hline & \multicolumn{2}{c}{$\stackrel{\text { Popular }}{\mathrm{M}}_{\mathrm{SD}}(\mathrm{N}=30)$} & \multicolumn{2}{c}{$\frac{\text { Isolated }}{\mathrm{M}}$} & $\mathrm{N}=30)$ & \multicolumn{2}{c}{$\frac{\text { Rejected }}{\mathrm{M}}(\mathrm{N}=30)$} \\
Male & 38.27 & 13.36 & 46.93 & 13.87 & 44.30 & 13.59 \\
Female & 43.80 & 10.60 & 31.60 & 15.69 & 42.20 & 11.55 \\
Combined & 41.04 & 11.48 & 39.27 & 14.78 & 43.25 & 12.57 \\
\hline
\end{tabular}


2. Intelligence. The results of the $I Q$ test indicate no main effect for social acceptance or any significant interaction effect for social acceptance, grade, and sex dimensions. The IQ data do not support the prediction of a difference by social acceptance groups in intelligence. Also, there is no support for the prediction that social acceptance would interact with other attribute variables on this covariate.

In summary, the only role-taking task to differ significantly among groups of popular, isolated, and rejected students was Chandler's role-taking task. This would indicate that the ability to control the self is significantly different among the social acceptance groups; with popular children performing best at this skill, followed by isolates, and then rejected students. The demographic variables SES and IQ do not differ significantly among groups of popular, isolated, and rejected children. However, it was found that female isolates had a higher SES than male isolates and female popular students, which created an interaction effect between social acceptance and sex. Role-Taking and the Classification of Social Acceptance

The next section will offer a further test of the third hypothesis and discuss in a more direct way the importance of each of the correlate measures in contributing to the variance in social acceptance. More specifically, a multiple discriminant function analysis was performed. First, a MANOVA was computed to determine whether the criterion groups 
(social acceptance) differ on the correlates (Chandler's task, Feffer's task, IQ, and SES). Second, the multiple discriminant function analysis was computed to determine which of the predictor variables were most effective in discriminating and classifying levels of social acceptance.

Analysis of mean vectors. For each of the criterion groups (popular, isolated, rejected) a mean score was computed on each predictor variable (see Table 9). The four means associated with any one of the three criterion groups constitute that group's mean vector. To determine whether the mean vectors of the three criterion groups are different from one another, a Wilk's lambda test was calculated. Only the Chandler role-taking task with a Wilk's lambda of .704 was significant, $\underline{F}(2,87)=18.27, \underline{p}<.001$. Since there was a significant difference among the criterion groups on at least one of the predictor variables, the multiple discriminant function analysis was computed.

Table 9

Group Means of Four Predictor Variables on Three Criterion Groups ( $N=90)$

\begin{tabular}{lrrrr} 
Predictor & & & \\
Variables & Popular & & Isolated & Rejected \\
Chandler & 8.33 & 13.27 & 15.80 \\
Feffer & 18.63 & 17.42 & 15.17 \\
IQ & 114.07 & 114.57 & 112.73 \\
SES & 41.03 & 39.27 & 43.23 \\
\hline
\end{tabular}

Discriminant function analysis. In this study, three multiple discriminant function analyses were calculated. 
The first analysis used the direct method in which all predictor variables were entered into the discrimination equations. The second and third analyses employed the Winresid procedure, which is analogous to a stepwise multiple regression analysis. The first Minresid used a maximum significance of $\underline{p}<.50$, the second Minresid used a $\underline{p}<.05$ to enter variables into the equation.

For the direct method, all four predictor variables were used and two discriminant function equations were derived. The first equation was found to account for $96.61 \%$ of the total discriminative power of the variables studied and for $32 \%$ of the total variance $\left(R^{2}=\cdot 32\right)$. The contribution of the remaining equation to group discrimination was $3.39 \%$. Chi square tests were computed for each of the two derived equations. Only the first discriminant function was found to be significant, $\chi^{2}=35.12, \underline{p}<.01$. The significant discriminant function equation was as follows:

$$
\underline{z}_{1}=.217 x_{1}-.204 x_{2}+.319 x_{3}-.589 x_{4}-5.741
$$

The standardized and unstandardized canonical discriminant function coefficients are presented for both discriminant equations (see Table 10).

In comparing the standardized canonical coefficients, the largest coefficient for function I was for Chandler's role-taking task. This would indicate that Chandler's task was the most effective predictor variable within the context of the corresponding discriminant equation. The second most effective predictor variable in discriminating social 
acceptance levels was the IQ score. The second discriminant function had higher coefficients for Feffer's task and SES.

Table 10

Standardized and Unstandardized Canonical Coefficients for Discriminant Functions I and II

\begin{tabular}{lcccc} 
& \multicolumn{4}{c}{ Coefficients } \\
\cline { 2 - 5 } Predictor & Standardized & Unstandardized \\
Variables & I & II & I & II \\
Chandler & 1.056 & .199 & .217 & .409 \\
Feffer & -.141 & .436 & -.204 & .634 \\
IQ & .359 & .272 & .319 & .242 \\
SES & -.080 & -.739 & -.589 & -.542 \\
\hline
\end{tabular}

Thus, it would appear that function I was concerned primarily with controlling the self and intelligence, while function II was concerned with interrelating multiple elements and socioeconomic status. These results support the prediction that performance on the role-taking tasks contribute to different proportions of the variance on measures of social acceptance. However, the data do not support the prediction that the role-taking tasks are both better discriminators of social acceptance than $I Q$ and SES.

In the Minresid, $\underline{p}<.50$ method, only two variables reached significance to enter into the analysis; Chandler's role-taking task, $\underline{F}(2,87)=18.27, \underline{p}<.001$, and $I Q, \underline{F}(4,172)=$ 9.27. $\underline{p}<.001$. The first resultant equation was found to account for $99.3 \%$ of the total discriminative power of the two variables studied and for $32 \%$ of the total variance $\left(R^{2}=.32\right)$. The contribution of the remaining equation totaled less than $1 \%$. The first discriminant function was found to 
be significant, $\boldsymbol{X}^{2}=33.79, \underline{p}<.001$. The significant discriminant equation was as follows: $\underline{z}_{1}=.222 \mathrm{x}_{1}+.322 \mathrm{x}_{2}-$ 6.439. A comparison of the standardized canonical coefficients indicated that Chandler's task was the most effective predictor variable in this equation; 1.08 for Chandler's task and .363 for IQ, respectively.

In the Minresid $\underline{p}<.05$ method, only Chandler's roletaking task reached significance to enter into the analysis, $\underline{F}(2,87)=18.27, \underline{p}<.001$. This produced only one discriminant function equation that accounted for $100 \%$ of the total discriminative power of the variable studied and for $29 \%$ of the total variance $\left(R^{2}=.29\right)$. This discriminant function equation was as follows: $\underline{z}=.2055 x_{1}-2.562$.

Classification results. To determine the effectiveness of the discriminant function equations in classifying children, a comparison was made between a student's actual social acceptance group and their predicted group membership. Individual scores were substituted into the equations to arrive at the percent of correct classification for each social acceptance group.

Using the direct method and all four predictor variables, the overall percent of grouped cases correctly classified was $55.56 \%$ (see Table 11 ). Correct classification was $73.3 \%$ of popular students; $33.3 \%$ of isolated students; and $60 \%$ of rejected students. Using the Minresid $\underline{p}<.50$ level and only Chandler and IQ scores, the overall percent of grouped cases correctly classified increases to $56.67 \%$. 
Table 11

Classification Results for Social Acceptance Using Four Predictor Variables

Actual

Group

Popular

Isolated

Rejected

$\frac{N}{30}$

30

30
Predicted Group Membership Popular Isolated Rejected 22 $(73.3 \%)$ 5 $(16.7 \%)$ 3 $(10.0 \%)$

10 $(33 \cdot 3 \%)$ 10 $(33 \cdot 3 \%)$ 10 $(33 \cdot 3 \%)$ 18 $(60.0 \%)$

Note. Percent of overall cases correctly

classified is $55.56 \%$. Prior probability is $33.3 \%$.

Correct classification of popular students improve to $76.7 \%$, and $36.7 \%$ for isolated students. Correct classification of rejected students decreases to $56.5 \%$. The Minresid $\underline{p}<.05$. using only Chandler's task, does not improve on the percentage of correct classification. In fact, the percentage of overall correct classification decreases to $52.22 \%$.

From the data it would appear that the most effective discriminant function equation to classify students into social acceptance groups involves two variables; Chandler's role-taking task and IQ. The overall percent of correct classification for this equation is about the same as using all four variables, but the use of two variables makes it more parsimonious, and thus more efficient. The data also indicate that popular and rejected students are the easiest to classify with the predictor variables used. Isolated students are the most difficult to classify, with the results being no better than chance. In addition, when 
popular and rejected students are misclassified, they were likely to be categorized as an isolate.

Summary

The results of the present study offer only partial support for the first hypothesis; that the role-taking task measuring interrelating multiple elements does not relate significantly to the role-taking task measuring controlling the self. The role-taking measures showed statistical significance in their relationship, but not practical significance. This would suggest that the measures may not be assessing the same underlying construct and may, as proposed, be measuring different constructs. There were also significant, but small, correlations between Chandler's task and IQ, Feffer's task and SES, and IQ and SES.

The second hypothesis was partially supported in that performance on both role-taking tasks differed by grade level. Also, the pattern of development was, as predicted, differed for each role-taking task. However, the prediction that the ability to interrelate multiple elements would show a significant increase between the second and fourth grades, and controlling the self would show a significant increase between the fourth and sixth grades was not supported by the data.

The third hypothesis was partially supported by the data. The prediction that those children having greater social acceptance by their peer group would score higher on the role-taking tasks was found true only for Chandler's 
role-taking task. The demographic variable of SES differed significantly between male and female isolates, and between female isolates and female popular students. Female isolates had the highest socioeconomic status. Intelligence was not found, by itself, to discriminate among levels of social acceptance. However, intelligence, in combination with Chandler's role-taking task, were found to be the most effective variables in correctly classifying students into social acceptance categories. Feffer's role-taking task did not significantly contribute to this classification process. Thus, the results only do not support the hypothesis that the role-taking abilities of interrelating multiple elements and controlling the self contribute more weight than the demographic variables of SES and IQ to social acceptance. 


\section{Discussion}

The present research explored the role-taking construct, its development over grade levels, and its relationship to social acceptance. In general, the results partially support the hypothesis that role-taking is not a unitary construct. The results confirm the hypothesis that the ability to interrelate multiple elements and control the self differ by age levels. However, the prediction that interrelating multiple elements would develop before the ability to control the self was not supported. The last hypothesis received partial support: the ability to control the self did contribute significantly to the variance in social acceptance. Although, this was not found to be true for the ability to interrelate multiple elements. In addition, intelligence, when used in combination with the ability to control the self, was a more effective predictor than interrelating multiple elements in classifying children into groups of popular, isolated, and rejected students. The discussion of the preceding results will be organized in the following manner. First, the results will be compared with previous research findings and past theory. In particular, the following themes will be discussed: 1) role-taking as a non-unitary construct; 2) the development of the component abilities and their relationship to the demographic variables of SES and IQ; 3) the relationship of the component abilities to social acceptance. Next, the implications for future research will be discussed. 
Finally, the present findings will be discussed in terms of the implication for delivery of psychological services in the schools.

Construct of Role-Taking

The first major hypothesis of this study was whether or not role-taking is a unitary construct or a construct composed of two component abilities. Recent trends in the roletaking literature strongly indicate that role-taking is not a unitary construct, but a composite of component abilities (Hollos, 1975; Kurdek, 1977; Piche, Michlin \& Rubin, 1975). Higgins (1981) outlines four possible theoretical dimensions of role-taking. Two of these dimensions of role-taking are the abilities to interrelate multiple elements and to control the self. Two role-taking tasks, which conceptualize as independently as possible each of these component abilities of role-taking, are Chandler's and Feffer's role-taking tasks (Higgins, 1981). It was predicted in the present study that the correlation between these two tasks would be nonsignificant. The correlation was significant, thus implying that they may be measuring the same ability, not two as predicted. However, when the correlation coefficient was squared to obtain the amount of common variance between the two role-taking tasks, the result was quite low. This indicates that for practical purposes the tests share little common variance and offers some support for the first hypothesis. 
The distinction between these component abilities may be important when comparing different role-taking tasks because the principle requirement of each task may be different (Higgins, 1981; Kurdek, 1977). The data from the study would support this notion. For Feffer's task, the subject is required to review a social situation and interrelate in a coordinated fashion the viewpoints of each character (Schall \& Feffer, Note 12). There is no need for the subject to suppress his or her own viewpoint in order to perform this task. In contrast, Chandler's role-taking task requires that the subject actively suppress or control his or her point of view to be successful on this task. In addition to comparing individual tasks, this conceptual difference is important because it may account for the relatively weak and inconsistent correlations found in studies of role-taking (Chandler, 1978; Glucksberg, Krauss \& Higgins, 1975; Shantz, 1975).

It has long been assumed that the low correlations among the role-taking tasks are due to the poor reliability of some of the instruments (Shantz, 1975), or that the low correlations are due to the different content domains of the role-taking tasks; spatial, affective, or cognitive. Ford (1979), in his review of the literature found little support for the idea that there is a greater relationship among tasks within the same domain than across domains. The results of this study offer support for a different thesis: that regardless of content domain, there are underlying 
process abilities that distinguish between role-taking tasks. These abilities may be interrelating multiple elements and controlling the self.

There was a finding of a low, but significant, correlation between Chandler's role-taking task and the Ammon's Quick Test. This finding is consistent with previous studies finding low to moderate correlations between roletaking and conventional measures of intelligence, but the strength of the relationship varies with the role-taking task and the type of intelligence test (Shantz, 1975). The Ammon's Quick Test did not correlate significantly with Feffer's role-taking task. This could mean that the ability to interrelate multiple elements is not related to a verbal receptive measure of intelligence, while the ability to control the self is related to this type of measure. The ability to interrelate multiple elements may correlate substantially with other measures of intelligence. It could also be that the significant correlation between Chandler's task and the Ammon's Quick Test is spurious to the extent that they both relate significantly with a third factor, i.e. verbal comprehension, or use combined groups whose mean values differ on one of the variables (McCall, 1970). The relationship between Feffer's role-taking task and SES indicates that as one increases in socioeconomic status, one's ability to interrelate multiple elements also increases. This may represent an actual relationship between these two factors, and may seem contrary to the notion that Piaget's 
constructs are universal across cultures and settings (Hollos, 1975; Hollos \& Cowan, 1973). However, it is well known that parental styles of child rearing differ by socioeconomic class. Middle-class parents tend to use more psychological and conceptually oriented punishments, while lower-class parents tend toward more physical means of punishment (Kephart, 1977). Hoffman (1970) found that various indices of social cognition (moral development) in a large number of studies are more consistently associated with predominantly conceptually oriented child rearing practices, as compared to assertion of parental power. Thus, it may be that interrelating multiple elements does not relate to SES per se, but to child rearing practices found within different socioeconomic classes.

Intelligence was also found to relate significantly with SES in this study. This relationship is consistent with the previous literature on these two variables. Matarazzo (1972), in reviewing the voluminous literature on SES and intelligence has found the average correlation coefficient to be .40 , as defined by any of the variety of indices of SES and IQ. This is not surprising when one considers that IQ is also related to each of the indices used to define SES in this study, education and occupation. Matarazzo (1972) reports a correlation coefficient of .50 between intelligence and educational attainment in school, and a correlation coefficient of .50 between intelligence and occupation. On the average, persons of below average 
intelligence are found in semi-skilled jobs, individuals of average intelligence in trades and skilled occupations, and those with superior scores are found in the professions or in executive positions in industry.

Role-Taking Development

The second hypothesis was that each of the component abilities of role-taking do not develop simultaneously among children from early to middle elementary grade levels. The difference by grade level on Chandler and Feffer's roletaking tasks supports this hypothesis. The results obtained are also consistent with other studies showing age-related changes in role-taking ability (DeVries, 1970; Feffer, 1970; Flavell, 1974; Selman \& Byrne, 1974). Overall, it would appear that the abilities to control the self and interrelate multiple elements develop with age.

It was predicted that the pattern of development would be different for both variables. This was found to be true and offers further support for the second hypothesis. However, it was also predicted that interrelating multiple elements would show a pattern of a large increase between second and fourth grades and a small increase between fourth and sixth grades. In addition, controlling the self was predicted to show a large increase between the fourth and sixth grades. These predictions were based on the logic that interrelating multiple elements is similar to, or another manifestation of, decentering, which is thought to be the prerequisite ability for the formation of cognitive 
operations in both the physical and social universe (Piaget \& Inhelder, 1969).

The pattern of development found was opposite of what was predicted. Chandler's task, or the ability to control the self, showed its largest developmental increase between the second and fourth grade, rather than between the fourth and sixth grades. Feffer's task, or the ability to interrelate multiple elements, showed about an equal increase between grade levels. Thus, the predictions were not supported, and are contrary to the second hypothesis. It may be that interrelating multiple elements is not another manifestation of decentering, and thus not expected to develop before the ability to control the self. Another explanation is that interrelating multiple elements is another manifestation of decentering, but decentering is not a prerequisite for the ability to control the self. It could also be that the results found are peculiar to the sample used in this study. Further investigation is needed to clarify this issue.

The data also indicate no sex difference on either of the role-taking tasks. This follows the pattern found in previous studies, where males and females perform in a similar manner on role-taking tasks (Burke \& Glenwick, 1978; Chandler et. al., 1974; Flavell et. al., 1968; Turnure, 1975). Thus, one can conclude that there is no evidence for a difference between males and females in the abilities to control the self or interrelate multiple elements. 
A finding inconsistent with previous investigations on intelligence is the difference among grade levels on the IQ measure. It was found that second graders scored significantly lower on this test than either fourth or sixth graders. One possible explanation is that because more second graders scored below 100 than fourth and sixth graders, the average for this grade was lowered. Another tenable explanation concerns the construction of the Ammon's Test. Where many intelligence tests use a deviation IQ to provide comparable scores at all age levels, the Ammon's Quick Test does not do this with children. The raw scores are converted into liA's and then used to compute IQ scores through the ratio formula: This leads to a situation where IQ variability is not constant at all age levels. Thus, unless the standard deviations of the IQ distribution remain constant with age, the IQ will not be compatible at different age levels (Anastasi, 1976). Theoretically then, the mean score for the second graders may be compatible with the fourth and sixth graders even though the actual scores are different. In other words, an IQ of 108 with an SD of 8 at age 7 , may be equal to an IQ of 116 with a standard deviation of 16 at age 10; if both are one standard deviation from a mean of 100. In essence then, the construction of the test may have led to numerical differences when no actual differences existed. Role-Taking and Social Acceptance

The third hypothesis was concerned with the relationship between role-taking and social acceptance. It was 
predicted that the tasks measuring interrelating multiple elements and controlling the self would discriminate social acceptance groups: Chandler's task, measuring controlling the self, discriminated among the social acceptance categories. Popular children were better at controlling the self than isolates and rejected students, and isolates were superior to rejected students. Interrelating multiple elements, as measured by Feffer's role-taking task, did not differ among these social acceptance groups, thereby giving only partial support to the third hypothesis. Also, it was predicted that the abilities to interrelate multiple elements and control the self would contribute more to the classification of social acceptance than SES and IQ. The multiple discriminant function analysis indicated that all four variables, as a set, could discriminate and classify children into social acceptance categories better than chance. A comparison of the standardized canonical coefficients indicate that Chandler's role-taking task was the most effective variable in classifying children into groups of popular, isolated, and rejected students. IQ was the second most important variable. The results are inconsistent with the prediction that the abilities to interrelate multiple elements and control the self are both greater factors in social acceptance than SES and IQ. These findings offer only partial support for the third hypothesis.

Several implications can be drawn from the preceding results. First, Piaget's (1926) notion that a child's 
social status or popularity is related to his or her ability to take another's viewpoint has not been entirely supported, but neither has it been refuted. The data would support that the role-taking ability to control the self is related to popularity, while the ability to interrelate multiple elements is not related to popularity. Second, one could speculate that interrelating multiple elements, as defined by this study, is not as critical to, or affected by, a subject's social interaction. This ability involves being able to understand the viewpoints of others in a situation and interrelate them in a coordinated fashion. The subject's viewpoint is not part of the interaction. In contrast, controlling the self, as defined by this study, involves the viewpoint of the subject in the social interaction which must be actively controlled or suppressed. The ability to control the self may be more essential to appropriate behavior and to accurately understand another person when you are part of the social interaction. In addition, this ability may be more prone to disruption or interference from affective stimulation than interrelating multiple elements because it is a skill required of the person engaged in the social situation. This would thereby affect the persons subsequent behavior and acceptance from peers. Thus, children may be popular because they can use this ability to control the self in situations where they are actively involved. Isolated and rejected children may have the ability to coordinate and understand viewpoints when they 
are not part of the interaction, but have difficulty in situations where they are actively involved.

Third, IQ, as in numerous studies, continues to be an important variable in social acceptance. However, the data indicate that $I Q$, only in combination with the ability to control the self, is effective at differentiating social acceptance groups.

The prediction that the social acceptance groups would differ in SES and IQ was not supported by the data, even though previous reviews on this subject have reported such differences (Schmuck \& Schmuck, 1975). There was, however, an interaction effect between sex and social acceptance on SES which supports previous findings (Brown \& Bond, 1955; Davis, 1957). The data indicate that female isolates have a significantly higher socioeconomic status than male isolates and female popular students. One could speculate that it helps to have similar background experiences, traditions, etc., if one is to be popular with peers. Also, it may be that females who are isolates from their peers are not well liked or sought after because of different background experiences, but are not disliked to the extent they are actively rejected. In addition, these female isolates, because of a different background experience, may be uncomfortable with the majority of their classmates and voluntarily withdraw or isolate themselves. Viale isolates are of a lower SES than female isolates, but not different from male popular and rejected students. It therefore can be concluded, that 
SES was less important among males in terms of social acceptance than females for this sample.

The classification results clearly indicate that popular and rejected children are the most accurately classified. These children represent the ends of the social acceptance spectrum. Another group of children with peer relationship problems are the isolates (Gottman, 1977; 0'Connor, 1969). These were the most difficult to classify. Their scores on the correlates did not cluster as tightly as did popular and rejected students, and therefore were more often misclassified. One tenable explanation is the means by which the students were initially classified. Students were classified as isolates on the basis of peer and teacher nominations. Standard peer nominations do not usually employ a category of isolate nominations. The effect of this additional category on the peer nomination scale may have led to the same phenomenon seen on many Likert-type scales, a tendency to choose the middle category rather than the extremes. This was seen particularly among female second and fourth grade students. At these grade levels twice as many girls were nominated as isolates rather than rejected. This effect was not seen with males or sixth grade girls. It could be that second and fourth grade girls were more unsure of their choices, or girls at these age levels are more fluid in terms of friendship choice and peer group interaction. The end result is an over representation of isolates, some of which may not be true isolates. 
Another explanation is that the isolates are not at any age level a homogeneous population. While some of the children may have significant peer relationship problems, others may be well adjusted. Thus, it appears that other criteria, in addition to peer and teacher nominations, may be needed to identify those isolates having peer relationship difficulties.

Overall, the general trends of the data can be summarized as follows: 1) Interrelating multiple elements is significantly, but not highly, related to controlling the self. 2) Both abilities increase with age, but the development of interrelating multiple elements does not appear to be a prerequisite ability for controlling the self. 3) Controlling the self is a significant role-taking variable in discriminating and classifying social acceptance groups. 4) Female isolates have a higher SES level than other social acceptance groups. 5) Popular children appear to be students from the dominant SES group. 6) IQ is an important variable in social acceptance, but only in conjunction with controlling the self. 7) Isolates are the most difficult social acceptance group to differentiate and classify students into, and more effective measurement techniques and/or predictor variables are needed for this group.

The ability to infer causality and generalize the findings of this sample to a larger population of elementary students must be tempered somewhat because of the characteristics of the subjects and design of the experiment. This 
design employed all attribute variables. These are variables that the experimenter cannot assign subjects to any of the levels of that factor. Since all the factors are attribute variables, the investigation should be classified as relational rather than truly experimental. Therefore, one cannot draw cause-and-effect conclusions from the results obtained. One can only say that controlling the self is related to social acceptance, not that it causes popularity or peer rejection.

In terms of external validity, the grade factor was a fixed factor. This implies that the results are generalized only to second, fourth, and sixth grades, not the entire elementary school population. The subjects were randomly selected from the population they represent, thereby increasing the external validity of the design. However, the subjects were all mainstreamed children. No subject was out of the classroom for more than $20 \%$ of the time to receive special services. Therefore, the results of the study are not directly applicable to special education populations. Implications for Future Research

The implication that role-taking is not a unitary construct has initially been explored. Future research in the area should attempt to determine more thoroughly the concept of component abilities of role-taking. Future projects could include some other role-taking tasks theoretically measuring controlling the self and interrelating multiple elements (see Appendix D). An inclusion of such tasks would 
allow a determination of whether tasks measuring controlling the self intercorrelate more highly with each other than any of them do with tasks measuring interrelating multiple elements (rather than comparing the intercorrelations to zero). This would afford a measure of the convergent and discriminant validity of these component abilities of role-taking (Campbell \& Fiske, 1959).

In terms of the developmental changes of these component abilities, the findings of the present study were based on cross-sectional methodology. The changes in the constructs of controlling the self and interrelating multiple elements were inferred from age differences in performance. A study could directly examine the change in controlling the self and interrelating multiple elements using a longitudinal design. Longitudinal data, even over relatively short periods, would provide needed information and a more coherent picture of developmental change, such as intra-individual changes.

An attempt could also be made to examine a more causal effect of these component abilities of role-taking on social acceptance. Of particular interest are the effects of the ability to control the self on social behavior and peer acceptance. Training studies could use control and placebo groups to help determine the effect of training students in controlling the self on social behavior and social acceptance. 
Also, future studies need to continue to account for the effects of intelligence on social acceptance. In addition, socioeconomic status needs to be accounted for when determining social acceptance levels, particularly with female subjects. Lastly, one needs to examine alternate strategies for the identification of those isolates who are truly experiencing social adjustment problems.

Summary of Discussion

Role-taking is significantly related to social acceptance, particularly the ability to control the self. Popular students, regardless of grade level or sex, showed more ability to control the self than either isolated or rejected students. Thus, controlling the self was linked to social acceptance and presumably actual behaviors across environments. Other role-taking tasks may be primarily measuring controlling the self and interrelating multiple elements, and this needs to be empirically demonstrated. This would offer further evidence to support the hypothesis that roletaking is not a unitary construct. Intelligence and SES also play a part in social acceptance, and the need to be further researched as concomitant variables to role-taking. Suggestions were made for including controlling the self in causal studies of social acceptance before implementing preventive programs in the primary grades. 
Appendix A

Correspondence 
To: Bart 0'Connor

Superintendent of Attleboro Schools

From: William Geary

RE: Dissertation research

"Role-taking ability and social acceptance among peers"

\section{Background}

Social acceptance by one's peers has been shown to be important to a child's mental health, particularly with peer rejection being associated with a wide variety of learning and emotional problems. One important social cognitive skill in initiating and maintaining peer relationships is role-taking. Role-taking is an ability to see the world from the perspective of another person: to understand another's spatial, cognitive, and affective orientation. The recent literature has strongly indicated that role-taking is not a unitary ability, but a composite ability made of two or more sub-skills. What needs to be done is a task analysis of role-taking to determine what these component skills are. In addition, the relationship of these component skills to social acceptance, at different ages, needs to be determined.

Method

What I would like to do is conduct a research project in the Attleboro School system that addresses the above needs. I would first need to administer a peer sociogram and teacher nomination scale to two or three classrooms at each grade level (grades 2, 4, and 6). This would take 30 
minutes of classroom time, and be done as a group procedure. From the peer sociogram and teacher nomination scale I would categorize students into popular, isolated, and rejected students. The students will not know what category they are in. Thirty students would then be randomly sampled from each category for a total sample population of 90 students. These children would then be given, on an individual basis, the role-taking tasks. This would take about 30 minutes per child.

This project will be supervised by William Vosburgh, Ph.D. from the University of Rhode Island. In addition, it will be monitored and approved at each stage by the three other members of the doctoral committee. All efforts will be taken to protect student confidentiality, and written parent permission will be obtained for each of the 90 students taking the role-taking tasks.

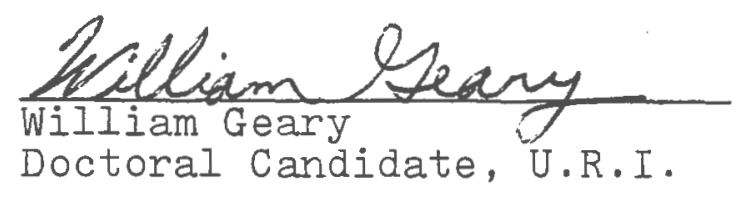


To: Parents of 2 nd, 4 th , and $6 \underline{t h}$ grade students

From: William P. Geary, M.S.

University of Rhode Island

Dr. Bart O'Connor, Ed.D.

Superintendent of Attleboro Schools

Regarding: Participating in "Understanding of Children's Social Skills Research Program".

Date: April 5, 1983

Over the past few years we, at the University of Rhode Island, have been interested in how elementary school children get along with each other. Our interest grew out of studies indicating that children who like, and are liked by others, enjoy school more and do better in their classwork. Because of this, we have developed a study to further define the social skills most effective in forming friendships and solving social problems. We will be giving students problems around social. situations to see how they respond. The information we get from your child will help us determine what are typical social skills for different grade levels, so that we may better understand, and intervene with children who are less skilled in their social interactions. We need 30 minutes of your child's time, and information we gather will be kept strictly confidential. This study has met the approval of the Attleboro School superintendent and the building principal. In addition, the University of Rhode Island has given me permission to conduct this study under their supervision. Since we are asking to take your child out of the regular classroom to conduct this study, we need your approval and permission. Please indicate your permission by signing below and returning the bottom portion of this page. If you have any questions about this study, you can call the following number any evening after 6 p.m.: (401) 433-3483.

Thank you for your time and cooperation.

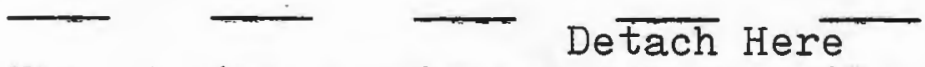

Yes, I give permission for my child to participate in the Social Skills Research Program.

Parent or Guardian

No, I do not give permission for my child to participate in the Social Skills Research Program. 
Please have your child return this form by April, 1983 to his or her classroom teacher. 
Appendix $B$

Sociometric Instruments and

Chandler's Role-Taking Task 
TEACHER NOMINATION SCALE

Because teachers are exposed to a wide range of students, their perceptions of how these students relate to one another have proven valuable in identifying children with peer problems. The literature has unfortunately been inconsistent in providing adequate guidelines in identifying children who have interpersonal difficulties and those who are well liked. For the purposes of this study, we have constructed our own operational definitions. Please indicate on the sheet provided those children in your class who are popular, isolated or rejected, according to the definitions Iisted below.

Popular - These are students who are well liked by the peer group because of their cooperative and friendly manner. They are active, independent, and often a leader among their peers. Generally, they are pleasant, have a good sense of humor, and supportive of others.

Isolate - These children almost always play and work by themselves. They are usually described as shy and withdrawn and "hoover" around the peer group. When they do interact, it is usually the result of initiation by others, and often they are teased. Since they are quiet, it is hard for their peers to get to know them. 
Rejected - This child has a way of upsetting everything when he or she gets into a group - doesn't share, loud, and tries to get everyone to do things their way. This child is actively disliked and often engaged in saying mean things, pushing others and starting fights. They are also noncompliant to requests and the rules of the group. 
Peer Nomination Scale

Name :

Grade :

List 3 children in your class you would most like to play with:

1.

2 .

3.

List 3 children in your class you do not like to play with: 1 .

2 .

3 .

Iist 3 children in your class who don't like to play with anybody.

I.

2 .

3. 
Chandler's Role-Taking Task

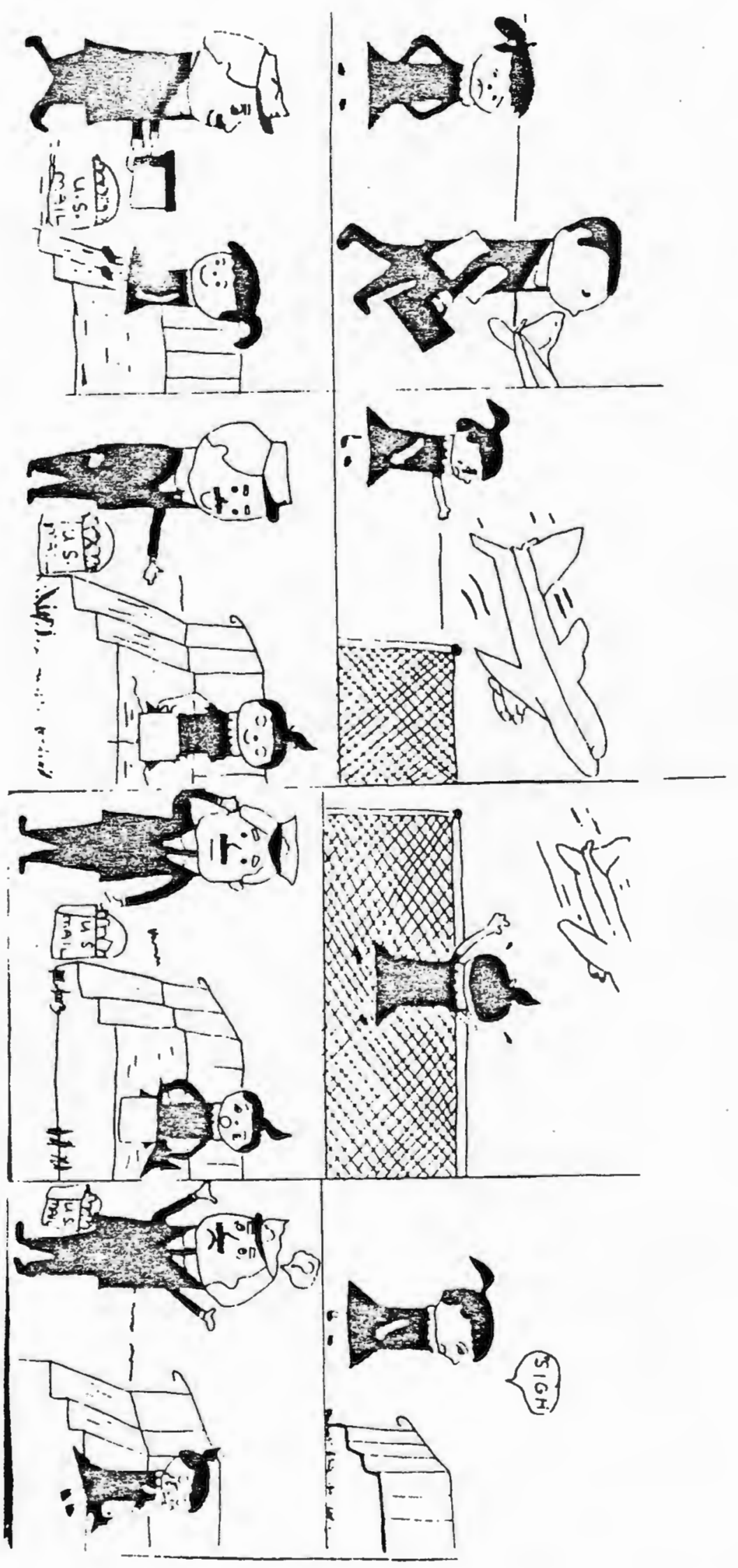


Appendix C

Summary Tables 
Summary of Cochran's $\underline{C}$ Test for Homogeneity of Variance $(\mathrm{N}=90)$

Variables

Feffer Role-Taking

Chandler Role-Taking

IQ

SES
$\underline{D F}$

4,18

4,18

4,18

4. 18
Obtained Value

.109

.131

.124

.092

Note. No obtained values exceeded a $\underline{p}<.01$ level of significance. 
Table 13

Means and Standard Deviations for the Correlates by Sex and Grade Levels ( $N=90$ )

Feffer's Role-Taking Task

$\underline{\text { Sex }}$

Male

Female

combined

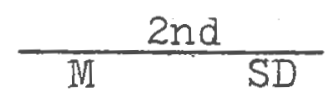

$14.50 \quad 6.12$

12.936 .92

13.726 .52

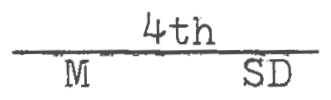

$17.83 \quad 6.74$

$16.90 \quad 7.13$

$17.37 \quad 6.94$

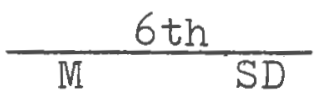

$18.97 \quad 5.80$

$21.30 \quad 5.11$

$20.14 \quad 5.46$

Chandler's Role-Taking Task

$\underline{\text { Sex }}$

Male

Female

combined

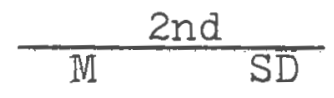

$17.07 \quad 3.82$

15.33

4.42

$16.20 \quad 4.12$

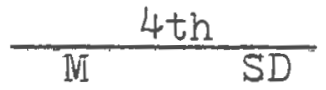

$10.27 \quad 4.96$

$12.73 \quad 3.83$

$11.50 \quad 4.40$

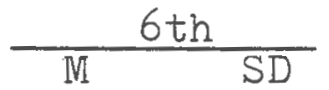

$10.00 \quad 2.62$

$9.40 \quad 3.44$

$9.70 \quad 3.03$

Hollingshead's Index of Social Position

$\underline{\operatorname{Sex}}$

Male

Female

Combined

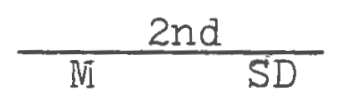

$45.53 \quad 10.17$

$39.87 \quad 12.97$

$42.70 \quad 11.57$

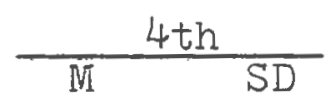

$43.87 \quad 15.00$

$37.47 \quad 11.40$

$40.67 \quad 13.20$

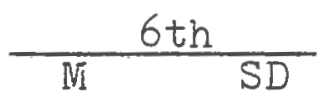

$40.07 \quad 15.63$ $40.27 \quad 13.47$ $40.17 \quad 14.55$

\section{Ammon's Quick Test}

$\underline{\operatorname{Sex}}$
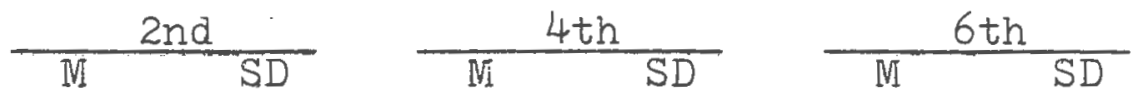

Male

$109.67 \quad 8.87$

117.33

7.42

114.80

13.11

Female

106.67

9.60

116.27

11.87

118.00

8.88

Combined

9.23

116.80

9.65

116.40

11.00 
Table 14

MANOVA Summary Table for Variables Grade, Sex and Social Acceptance on All Correlates $(N=90)$

Grade by Social Acceptance by Sex

\begin{tabular}{|c|c|c|c|c|}
\hline Test Name & Value & Hypoth. DF & Error DF & Approx. F \\
\hline Pillais & .12361 & 16 & 288.00 & .57399 \\
\hline Jotellings & .13021 & 16 & 270.00 & .54931 \\
\hline Vilks & .88087 & 16 & 211.44 & .56022 \\
\hline
\end{tabular}

Social Acceptance by Sex

\begin{tabular}{|c|c|c|c|c|}
\hline Test Name & Value & Hypoth. DF & Error DF & Approx. F \\
\hline Pillais & .20438 & 8 & 140.00 & $1.99188^{*}$ \\
\hline otellings & .23446 & 8 & 136.00 & $1.99293^{*}$ \\
\hline Jilks & .80360 & 8 & 138.00 & $1.99281 *$ \\
\hline
\end{tabular}

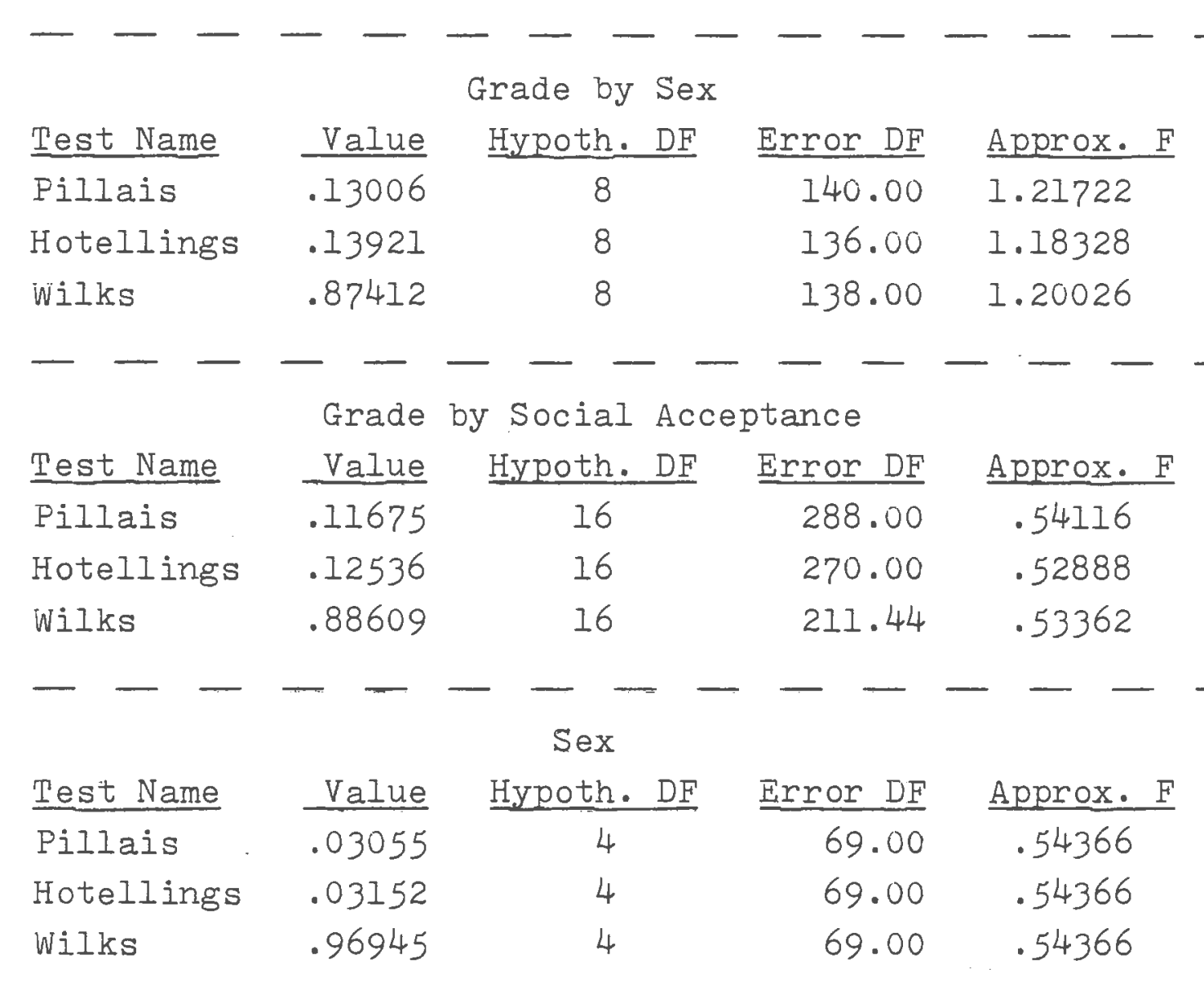

\footnotetext{
$\begin{aligned} * p & <.05 \\ * * \bar{p} & <.001\end{aligned}$
} 
Table 14

MANOVA Summary Table for Variables Grade, Sex and Social Acceptance on All Correlates $(N=90)$

Social Acceptance

\begin{tabular}{|c|c|c|c|c|}
\hline est Name & Value & Hypoth. DF & Error DF & Approx. F \\
\hline Pillais & .47770 & 8 & 140.00 & $5.49149 * * *$ \\
\hline otellings & .86084 & 8 & 136.00 & $7.31718 * * *$ \\
\hline $1 \mathrm{ks}$ & .53212 & 8 & 138.00 & $6.39753 * *$ \\
\hline
\end{tabular}

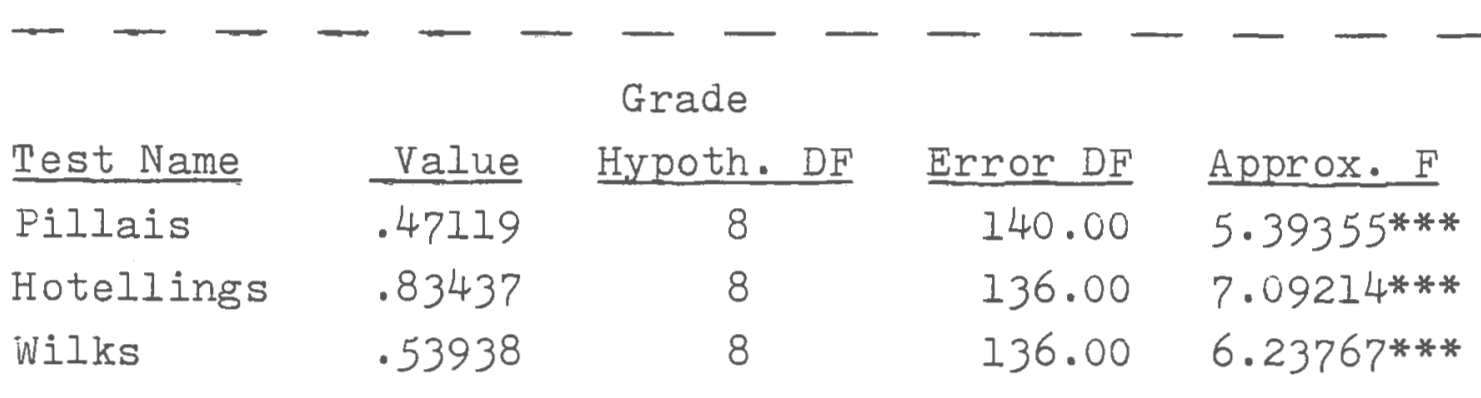

$\begin{aligned} * p & <.05 \\ * * * \bar{p} & <.001\end{aligned}$ 
Appendix D

Role-Taking Nieasures 
Role-Taking Measures

\section{Controlling the Self}

1. Chandler's Task

2. Flavell's Apple-dog Story

3. Piaget's Three Mountain Task

4. Flavell's Communication Task II

5. Flavell's NickelDime Game

6. Glucksberg \& Kraus Referential Communication Task

7. Baldwin \& Garvey Identification Task

8. Rothenberg's Affective Role-Taking Task
Interrelating Nultiple Elements

1. Feffer's Role-Taking Task

2. Selman's Social Dilemmas

3. Miller, Kessell \& Flavell's Recursive Thinking Task

4. Borke's Interpersonal Perception Test

5. Fesbach \& Roe's Affective Situations 
Reference Notes

1. Chandler, M. J. Egocentrism and childhood psychopathology: The development and application of measurement techniques. Paper presented at the biennial meeting of the Society for Research in Child Development, Minneapolis, March, 1971.

2. Geary, W. P. The relationship between role-taking and means-end problem solving and sociometric status in elementary school children. Unpublished manuscript, University of Rhode Island, 1981.

3. Kuhn, D. The development of role-taking ability. Unpublished manuscript, Columbia University, 1972.

4. Finley, G. E., French, D., \& Cowan, P. Egocentrism and popularity. Paper presented at the XIV Inter-American Congress of Psychology, San Paulo, 1973.

5. Rothbaum, F. Taking the perspective of another: A study of 11 and 13 year old children. Unpublished manuscript, Yale University, 1973.

6. Ispa, J. Familiar and unfamiliar peers as havens of security for Soviet nursery children. Paper presented at biennial meeting of the Society for Research in.Child Development, New Orleans, 1977.

7. Hymel, S. \& Asher, S. R. Assessment and training of isolated children's social skills. Paper presented at the biennial meeting of the Society for Research in Child Development, New Orleans, LA, 1977 .

8. Laubengayer, N. C. The effects of training on the spatial egocentrism of preschoolers. Unpublished master's thesis, University of Minnesota, 1965.

9. Douglas, E. C. The effect of spatial training on spatial egocentrism: Unpublished master's thesis, University of Georgia, 1971.

10. Elardo, P. Project AWARE: A school program to facilitate the social development of children. Paper presented at the Fourth Annual H. Blumberg Symposium, Chapel Hill, North Carolina, 1974. 
11. Sells, S. B. \& Roff, M. Peer acceptance, rejection and personality development: Final Report, Project No. OE 5-04I?. U. S. Department of Health, Education \& Welfare, 1967.

12. Schnall, M., \& Feffer, Mi. H. Mianual for the scoring of the role-taking task. Unpublished manuscript, undated. (Available from ADI Auxiliary Publications Project, Photoduplication Service, Library of Congress, Washington, D. C. 20540. Order No. 9010. Remit $\$ 13.50$ for microfilm or $\$ 21.50$ for photocopies. Checks payable to: Chief of Photoduplication Service, Library of Congress.)

13. Hollingshead, A. B. Two-factor index of social position. Unpublished manuscript, Yale University, 1957. 
References

Aboud, F. E. Egocentrism, conformity, and agreeing to disagree. Developmental Psychology, 1981, 17. 791-799.

Amidon, E., \& Hoffman, C. B. Can teachers help the socially rejected? Elementary School Journal, 1966, 66, 149154 .

Ammons, R. B., \& Ammons, C. H. The Quick Test (QT): Provisional manual. Psychological Reports, 1962, 11, $111-161$.

Anastasi, A. Psychological testing (4th Ed.). New York: MacMillan Publishing Co., 1976.

Asher, S. R., \& Hymel, S. Children's social competence in peer relations: Sociometric and behavioral assessment. In J. D. Wine \& M. D. Smye (Eds.), Social competence. New York: Guilford Press, in press.

Asher, S. R., Singleton, I. C., Tinsley, B. R., \& Hymel, S. A reliable sociometric measure for preschool children. Developmental Psychology, 1979, 15, 443-444.

Baldwin, W. K. The social position of the educable mentally retarded child in the regular grades in the public schools. Exceptional Child, 1958, 25, 106-108.

Barbe, W. B. Peer relationship of children of different levels. School and Society, 1954, 80, 60-62.

Barclay, J. R. Sociometric choices and teacher ratings as predictors of school dropouts. Journal of School Psychology, 1966, 4, 40-44.

Berndt, T. J. Relations between social cognition, nonsocial cognition, and social behavior: The case of friendship. In J. H. Flavell \& I. Ross (Eds.), Social cognitive development: Frontiers and possible futures. New York: Cambridge University Press, 1981.

Bonney, M. E. Relationship between social success, family size, socioeconomic home background and intelligence among school children in grades III to V. Sociometry, $1944,2,26-39$. 
Bonney, M. E. Choosing between the sexes on a sociometric measurement. Journal of Social Psychology, 1954, 39 , 99-114.

Bonney, M. E. Assessment of efforts to aid socially isolated elementary school pupils. Journal of Educational Research, 1971, 64, 359-364.

Bradley, F. O., \& Newhouse, R. C. Sociometric choice and self-perceptions of upper elementary school children. Psychology in the Schools, 1975, 12, 212-219.

Brown, W. H., \& Bond, I. B. Social stratification in a 6 th grade class. Journal of Educational Research, 1955 , 48, 539-543.

Buckley, N., Siegal, I. S., \& Ness, S. Egocentrism, empathy and altruistic behavior in young children. Developmental Psychology, 1979, 15, 329-330.

Burgess, T. C., \& Wright, D. D. Seventh-grade evaluation of the Ammons Quick Test. Psychological Reports, $1962,10,791-794$.

Burka, A. A., \& Glenwick, D. S. Egocentrism and classroom adjustment. Journal of Abnormal Child Psychology, $1978,6,61-70$.

Bush, P. L., Ford, R. C., \& Schulman, J. L. Stability of sociometric responses in classrooms. Journal of Genetic Psychology, 1973, 123, 69-84.

Campbell, D. T., \& Fiske, D. W. Convergent and discriminant validation by the multitrait-multimethod matrix. Psychological Bulletin, 1959, 56, 81-105.

Cannon, K. I. The relationship of social acceptance to SES and residence among high school students. Rural Sociology, 1957, 22, 142-148.

Chandler, J. J. Egocentrism in normal and pathological childhood development. In W. Hartup \& J. Dewitt (Eds.), Determinants of behavioral development. New York; Academic Press, 1972.

Chandler, M. J. Egocentrism and antisocial behavior: The assessment and training of social perspective-taking skills. Developmental Psychology, 1973, 2, 326-332. 
Chandler, J. J., Greenspan, S., \& Barenboim, C. Assessment and training of social perspective-taking and referential communication skills in institutionalized emotionally disturbed children. Developmental Psychology, $1974,10,546-553$.

Childers, P., \& Matuseak, I. Social-emotional maturity correlates of achievement and adjustment in kindergarten and first grade. Psychology in the Schools, $1972,2,396-403$.

Corsaro, W. A. Friendship in the nursery school: Social organization is a peer environment. In S. R. Asher \& J. M. Gottman (Eds.), The development of children's friendships. New York: Cambridge University Press, 1981 .

Cowen, E. I., Pederson, A., Babigian, H., Izzo, I. D. , \& Trost, M. A. Long term follow-up of early detected vulnerable children. Journal of Consulting and Clinical Psychology, 1972, 41, 438-446.

Cronback, L. J., \& Meehl, P. E. Construct validity in psychological tests. Psychological Bulletin. 1955, 22, 281-302.

Damon, w. The social world of the child. San Francisco: Jossey-Bass, 1978 .

Davis, J.A. Correlates of SES among peers. Journal of Educational Research, 1957, 50, 561-569.

DeVries, $R$. The development of role-taking as reflected by behavior of bright, average, and retarded children in a social guessing game. Child Development, 1970, 4l, 759-770.

Elkins, D. Some factors related to the choice status of ninety eighth-grade children in a school society. Genetic Psychology Monographs, 1958, 58, 207-272.

Feffer, Ni. The cognitive implications of role-taking behavior. Journal of Personality, 1959, 27, 152-168.

Feffer, J. Developmental analysis of interpersonal behavior, Psychological Review, 1970, 27, 197-214.

Feffer, M., \& Gourevitch, V. Cognitive aspects of roletaking in children. Journal of Personality, 1960, 28, 383-396. 
Feffer, M., \& Suchatliff, I. Decentering implications of social interactions. Journal of Personality and Social Psychology, 1966, 4, 415-422.

Fine, G. A. Friends, impression management, and preadolescent behavior. In S. R. Asher \& J. Ni. Gottman (Eds.), The development of children's friendships. New York: Cambridge University Press, 1981.

Fine, G. A., \& Kleinman, S. Rethinking subculture: An interactionist analysis. American Journal of Sociology, $1979,85,1-20$.

Flavell, J.H. Role-taking and communication skills in children. Young Children, 1966, 21, 164-177.

Flavell, J. H. The development of inferences about others. In T. Mischel (Eds.), Understanding other persons. Oxford, England: Blackwell, Basil, Mott, 1974.

Flavell, J. H., Botkin, P., Fry, C., Wright, J., \& Jarvis, P. The development of role-taking and communication skills in children. New York: Wiley, 1968.

Flavell, J. H., \& Ross, I. Social cognitive development: Frontiers and possible futures. New York: Cambridge University Press, 1981.

Ford, M. E. The construct validity of egocentrism. Psychological Bulletin, 1979, 86, 1169-1188.

French, D. C., \& Tyne, T. F. The identification and treatment of children with peer relationship difficulties. In J. P. Curran \& P. M. Monti (Eds.), Social skills training: A practical handbook for assessment and treatment. New York: Guilford Press, 1982.

Freud, A., \& Dann, S. An experiment in group upbringing. Psychoanalytic Study of the Child, 1951, 6, 127-168.

Fry, C. I. Training children to communicate to listeners. Child Development, 1966, 27, 675-685.

Fry, C. I. Training children to communicate to listeners who have varying listener requirements. Journal of Genetic Psychology, 1969, 114, 153-166.

Gallagher, J. J. Peer acceptance of highly gifted children in elementary school. Elementary School Journal, 1958, 58, 465-470. (a) 
Gallagher, J. J. Social status of children related to intelligence, propinquity, and social perception. Elementary School Journal, 1958, 58, 225-231. (b)

Glucksberg, S., Krauss, R., \& Higgins, E. T. The development of referential communication skills. In F. D. Horowitz (Ed.), Review of child development reasearch (Vol. 4). Chicago: University of Chicago Press, 1975.

Gottman, J. M. Toward a definition of social isolation in children. Child Development, 1977, 48, 513-517.

Gottman, J. M., Gonso, J., \& Rasmussen, B. Social interaction, social competence and friendship in children. Child Development, 1975, 46, 709-718.

Green, K. D., Forehand, R., Beck, S. J., \& Vost, B. An assessment of the relationship among measures of children's social competence and children's academic achievement. Child Development, 1980, 51, 1149-1156.

Gronlund, N. E. Relationships between the sociometric status of pupils and teacher's preference for or against having them in class. Sociometry, 1953, 16, 142-150.

Grossman, B., \& Wrighter, J. The relationship between selection-rejection and intelligence, social status, and personality among sixth grade children. Sociometry, $1948,11,346-355$.

Hartup, W. W. Peer interaction and social organization. In P. H. Mussen (Ed.), Carmichael's manual of child psychology. New York: Wiley, 1970 .

Hartup, w. W. Children and their friends. In H. MoGurk (Ed.), Issues in childhood social development. Iondon: Methuen, 1978.

Higgins, E. T. Social class differences in verbal communication accuracy: A question of "Which question?". Psychological Bulletin, 1976, 83, 695-714.

Higgins, E. T. Role-taking and social judgment: Alternative developmental perspectives and processes. In J. H. Flavell \& I. Ross (Eds.), Social cognitive development: Frontiers and possible futures. New York: Cambridge University Press, 1981.

Higgins, E. T., \& Parsons, J. E. Social cognition and the social life of the child: Stages as subcultures. In E. T. Higgins, D. N. Ruble, \&W. W. Hartup (Eds.), Social cognition and social development: Developmental issues. New York: Cambridge University Press, 1983. 
Hill, K. T. Relation of test anxiety, defensiveness and intelligence to sociometric status. Child Development, 1963, 34, 767-776.

Hoffman, M. I. Moral development. In P. H. Mussen (Ed.), Carmichael's manual of child psychology. New York: Wiley, 1970.

Hollos, M. Logical operations and role-taking abilities in two cultures: Norway and Hungary. Child Development, $1975,46,638-649$.

Hollos, M., \& Cowan, P. A. Social isolation and cognitive development: Logical operations and role-taking abilities in three Norwegian social settings. Child Development, 1973, 44, 630-641.

Janes, C., \& Hesselbrock, V. Problem children's adult adjustment predicted from teacher ratings. American Journal of Orthopsychiatry, 1977, 48, 300-309.

Joesting, J., \& Joesting, R. Comparison of scores on Quick Test and Stanford-Binet form L-Mi. Psychological Reports, 1971, 29, 1178 .

Johnson, D. W. Affective perspective taking and cooperative predisposition. Developmental Psychology, 1975, 11, 869-870.

Johnson, G. 0. A study of the social position of mentally handicapped children in regular grades. American Journal of Mental Deficiency, $1950,55,60-89$.

Kephart, W. M. The family, society, and the individual. Boston: Houghton Mifflin, I977.

Kirk, S. A. Research in education. In H. A. Stevens \& R. Heber (Eds.), Mental Retardation. Chicago: University of Chicago Press, 1964.

Kohlberg, I. Stage and sequence: The cognitive developmental approach to socialization. In D. Goslin (Ed.), Handbook of socialization theory and research. Chicago: Rand McNally, 1969.

Kraus, R. M., \& Glucksberg, S. The development of communication: Competence as a function of age. Child Development, $1969,40,255-266$. 
Kun, A., Parsons, J. E., \& Ruble, D. N. Development of integration processes using ability and effort information to predict outcome. Developmental Psychology, $1974,10,721-732$.

Kurdek, L. A. Convergent validation of perspective taking: A one year follow-up. Developmental Psychology, 1977, $13,172-173$.

Livesley, W. J., \& Bromley, D. B. Person perception in childhood and adolescence. London: Wiley, 1973.

Marsh, D. T., Serafica, F. C., \& Barenboim, C. Interrelationships among perspective taking, interpersonal problem solving, and interpersonal functioning. The Journal of Genetic Psychology, 1981, 138, 37-48.

Matarazo, J. D. Wechsler's measurement and appraisal of adult intelligence ( 5 th ed.). Baltimore: Williams \& Wilkins, 1972 .

MicCall, R. B. Fundamental statistics for psychology. New York: Harcourt, Brace \& World, 1970.

Miller, P. H., Kessel, F. S., \& Flavell, J. H. Thinking about people thinking about people thinking about....: A study of social cognitive development. Child Development, 1970, 41, 613-623.

Miller, R. V. Social status and socioempathic differences among mentally superior, mentally typical and mentally retarded children. Exceptional Children, 1956, 23, 114-119.

Murray, H. A. Thematic Apperception Test. Cambridge, Mass.: Harvard University Press, 1943.

Novak, D. W. Children's responses to imagining peers labelled as emotionally disturbed. Psychology in the Schools, 1975, 12, 103-106.

O'Connor, R. D. Modification of social withdrawal through symbolic modeling. Journal of Applied Behavior Analysis, $1969, \underline{2}, 1 \frac{5-22}{}$.

O'Malley, P. M., \& Bachman, J. G. Longitudinal evidence for the validity of the Quick Test. Psychological Reports, $1976,38,1247-1252$.

Paramesh, C. R. Relationship between Quick Test and WISC-R and reading ability as used in a juvenile setting. Perceptual and Motor Skills, $1982,55,881-882$. 
Peevers, B. H. \& Secord, P. F. Developmental changes in the attribution of descriptive concepts to persons. Journal of Personality and Social Psychology, 1973, 27. $120-128$.

Piaget, J. The language and the thoughts of the child. New York: Harcourt, 1926.

Piaget, J. The moral judgment of the child. New York: The Free Press, 1965. (Originally published, 1932.)

Piaget, J. Six psychological studies. New York: Random House, 1967.

Piaget, J. Piaget's theory. In P. H. Mussen (Ed.), Carmichael's manual of child psychology, (Vol. I). New York: Wiley, 1970.

Piaget, J., \& Inhelder, B. The child's conception of space. London: Routledge \& Kegan Paul, 1956.

Piaget, J., \& Inhelder, B. The psychology of the child. New York: Basic Books, 1969.

Piche, G. L., Michlin, M. L., Rubin, D. E., \& Johnson, F. L. Relationships between fourth grader's performance on selected role-taking tasks and referential communication accuracy tasks. Child Development, 1975, 46, 965-969.

Roff, M. Childhood social interactions and young adult bad conduct. Journal of Abnormal and Social Psychology, $1961,63,333-337$.

Roff, M., Sells, S. B., \& Golden, M. M. Social adjustment and personality development in children. Ninneapolis: University of Niinnesota Press, 1972.

Rountree, P. T., Caldwell, B. A., \& Webb, R. An examination of the relationship between role-taking and social competence. Child Study Journal, 1981, 11, 253-262.

Rubin, K. H. Egocentrism in childhood: A unitary construct? Child Development, 1973, 44, 102-110.

Rubin, K. H., \& Schneider, F. W. The relationship between moral judgment, egocentrism, and altruistic behavior. Child Development, $1973,44,661-665$.

Schmuck, R. A., \& Schmuck, P. A. Group processes in the classroom. Dubuque, Iowa: Brown, 1975. 
Selman, R. I. The relation of role-taking to the development of moral judgments in children. Child Development, $1971,42,79-91$. (a)

Selman, R. I. Taking another's perspective: Role-taking development in early childhood. Child Development, 1971 , 42, 1721-1734. (b)

Selman, R. I. Stages in role-taking and moral judgments as guides to social intervention. In T. Lickona (Ed.), Main and morality. New York: Hold, Rinehart \& Winston, 1974.

Selman, R. I. The child as a friendship philosopher. In S. R. Asher \& J. M. Gottman (Eds.), The development of children's friendships. New York: Cambridge University Press, 1981.

Selman, R. I., \& Byrne, D. F. A structured developmental analysis of levels of role-taking in middle childhood, Child Development, 1974, 45, 803-806.

Shantz, C. U. The development of social cognition. In E. M. Hetherington (Ed.), Review of child development research Vol. 5. Chicago: University of Chicago Press, 1975 .

Shantz, C. U., \& Wilson, K. Training communication skills in young children. Child Development, 1972, 43. 118-122.

Singleton, I. C., \& Asher, S. R. Peer preferences and social interaction among third-grade children in an integrated school district. Journal of Educational Psychology, $1977,69,330-336$.

Spivack, G., \& Shure, M. B. Social adjustment of young children. San Francisco: Jossey-Bass, 1974.

SPSS-X: User's guide. New York: McGraw-Hill, 1983.

Stengel, E. Suicide and attempted suicide. Middlesex: Peguin, 1971.

St. John, N. H., \& Lewis, R. G. Race and the social structure of the elementary classroom. Sociology of Education, 1975. 48, 346-368.

Straus, J. S., Harder, D., \& Chandler, M. Egocentrism in children of parents with a history of psychotic disorders. Archives of General Psychiatry, 1980, 36. $191-196$. 
Sullivan, E. U., \& Hunt, D. E. Interpersonal and objective decentering as a function of age and social class. Journal of Genetic Psychology, 1967, 110, 199-210.

Thompson, J. M., \& Sones, R. A. Education Apperception Test. Los Angeles: Western Psychological Services,

Turnure, C. Cognitive development and role-taking ability in boys and girls from 7 to 12. Developmental Psychology, 1975, 11, 202-209.

Tyne, T. F., \& Geary, W. Patterns of acceptance-rejection among male-female elementary school students. Child Study Journal, $1980,10,179-190$.

Ulman, C. A. Teachers, peers, and tests as predictors of adjustment. Journal of Educational Psychology, 1957, $48,257-267$.

Vance, H., Blixt, S., \& Ellis, C. Equivalence of forms one and three of the Quick Test. Psychological Reports, $1980, \underline{46}, 1184-1186$.

Winer, B. J. Statistical principles in experimental design (2nd Ed.). New York: McGraw-Hill, 1971. 